\title{
Socioscientific Issues Thinking and Action in the Midst of Science-in-the-Making
}

\author{
Benjamin C. Herman ${ }^{1} \cdot$ Michael P. Clough $^{2} \cdot$ Asha Rao $^{3}$
}

Accepted: 10 November 2021 / Published online: 8 January 2022

(c) The Author(s), under exclusive licence to Springer Nature B.V. 2021

\begin{abstract}
Like all SSI, the COVID-19 pandemic requires decisions that are contentious, involve scientific thinking, and vary across social groups. This investigation determined how perceptions about COVID-19 science and sociocultural membership associate with 557 university biology students': (1) COVID-19 behaviors after stay-at-home orders and (2) support for future societal COVID-19 responses. Hierarchical moderated multiple regression analyses demonstrate that students' COVID-19 mitigating actions after stay-at-home orders were significantly and positively associated with, in order of importance: (1) higher levels of COVID-19 spread prevention knowledge; (2) espousing more liberal, as opposed to conservative, political orientations; (3) being female; and (4) increased disbelief of COVID19 misinformation/disinformation claims. Furthermore, the students' political orientation moderated the relationship between their trust in scientific models to guide COVID-19 decisions and their personal COVID-19 actions, with trust in scientific models to guide COVID-19 decision-making being a significant positive predictor of moderate, conservative, and very conservative student groups' COVID-19 mitigating actions. Conversely, there was no association between trust in scientific models to guide COVID-19 decisionmaking and very liberal and liberal students' conducting COVID-19 actions. Hierarchical moderated multiple regression analyses revealed that students' support for societal-wide COVID-19 mitigating measures going forward is positively associated with, in order of importance: (1) espousing more liberal, as opposed to conservative, political orientations; (2) higher levels of COVID-19 spread prevention knowledge; (3) increased disbelief of COVID-19 misinformation/disinformation claims; (4) trust in scientific models for guiding COVID-19 decision-making; and (5) beliefs that factors beyond science and technology (e.g., personal actions) are necessary for pandemic resolution. Implications discussed include the importance for helping students analyze how sociocultural membership, personal biases, and trust in science interactively influence socioscientific decision-making. Further recommendations discussed include how science communication strategies must account for sociocultural variance in order to optimize trust in science and reasoned and responsible action.
\end{abstract}

Benjamin C. Herman

bcherman@tamu.edu

Extended author information available on the last page of the article 


\section{Introduction}

Socioscientific issues (SSI) are societal problems involving the intersection of scientific knowledge with complex social and cultural considerations. Examples of SSI include anthropogenic climate change, vaccinations, water fluoridation, genetically modified organisms, and the current COVID-19 pandemic. SSI may not only involve well-established scientific knowledge, like in the case of climate change science and the overwhelming safety of long-standing vaccinations, but they can also entail even more complex situations involving science-in-the-making (Latour, 1987) - exemplified in the ongoing COVID-19 pandemic. All SSI, whether involving well-established science or science-in-the-making, require policymakers and citizens to demarcate authentic scientific knowledge from pseudoscientific misinformation and disinformation to make judicious decisions.

However, SSI engagement is not solely determined by one's scientific knowledge. Because SSI by definition involve science and society, sociocultural factors often play a role in how people consider scientific information and their SSI decision-making even when the relevant science is well-established (Herman 2015, 2018; Hodson, 2009; National Academies of Sciences, Engineering, and Medicine (NASEM), 2017). Therefore, with contentious SSI, issues of science beliefs and trust, and their impact on action and support for SSI resolution are not uniform among individuals, and become increasingly complex when accounting for people's sociocultural group membership. This study sought to empirically investigate how science-related knowledge and beliefs and sociocultural factors associate with post-secondary biology students' decisions while in the midst of the COVID-19 pandemic.

\section{Literature Review}

Authentic scientific knowledge regarding multivariate systems is often not as straightforward as policymakers and citizens expect, and school science generally conveys. In Unsimple Truths, philosopher of science Mitchell (2009) writes that:

Policymakers would like neat, certain answers to questions of risk, so that an easily enforceable policy can be made. ... however, fixed probability assignments and law-governed prediction-and-act models cannot reflect our scientific knowledge in many of these situations. (p. 103)... If we project the overly simplistic old views of science as the epistemology of science, then when simple explanations and methods fail in complex situations, it appears to policymakers that science fails. The danger is that holding science up to the wrong standard will diminish the value of what science discovers about nature, and could create an environment in which science is no longer consulted to inform policy. (p. 118)

Policymakers and the general public too often suffer from misconceptions regarding standards of confidence for scientifically supported ideas, misunderstand the meaning of scientific consensus (Powell, 2016), and often wrongly seek unreasonable levels of certainty before being willing to accept an idea and take appropriate action regarding it (Mitchell, 2009). Yearly (1996) and Rudolph (2007) argue that some policymakers and business people use uncertainty to create unreasonable doubt and inaction on public policy matters. Thus, accurate and effective history and nature of science teaching and learning play an important role in scientific literacy efforts aimed at promoting more informed socioscientific decision-making. But such efforts must be done judiciously. The deconstruction 
of science by scholars in the social studies of science has, unwittingly, played a role in creating distrust in science. Latour (2004), a noted scholar in the field of science and technology studies, writes:

Do you see why I am worried? I myself have spent some time in the past trying to show " "the lack of scientific certainty" inherent in the construction of facts. I too made it a " primary issue'." But I did not exactly aim at fooling the public by obscuring the certainty of a closed argument - or did I? After all, I have been accused of just that sin. ...In which case the danger would no longer be coming from an excessive confidence in ideological arguments posturing as matters of fact-as we have learned to combat so efficiently in the past-but from an excessive distrust of good matters of fact disguised as bad ideological biases! (p. 227)

Trust is a broad notion entailing perceptions of integrity, dependability, and/or competence (Hon \& Grunig, 1999; Rahn \& Transue, 1998; Roduta-Roberts et al., 2011), and it is central to the concept of social capital (Mondak, 1988); the shared values and understanding that enables reliance among people that is essential for working together. Studies consistently show that general trust in science is high (Gauchat, 2011, 2012; National Science Board, 2016; Pew Research Center, 2015), and the broad tacit public trust in science and technology is also evident in the conduct of citizens in everyday life. For instance, most all people in developed nations have great trust in transportation vehicles and systems; are confident that plentiful food and other necessities will be replenished in stores and available for purchase; that potable water will flow to and sewage away from their living quarters; expect their communication devices to work; and rely on modern medicine to treat medical issues. None of this, including Earth's human population nearing 8 billion and a life expectancy nearing 73 years (United Nations, 2019), would be possible without deferentially trusting science and technology. Even those who deny the COVID pandemic and related public health recommendations still, with rare exceptions, seek medical treatment if they become seriously ill. Both implicit action and explicit opinion express general trust in science and technology.

However, trust in science and technology is quite different when the public is faced with what it perceives as a controversial SSI. With such issues, trust is no longer deferential, and decision-making becomes more explicit and purposeful. In these instances, a host of factors come into play including perceptions about the validity and nature of science (NOS), the latter entailing the ontological and epistemological assumptions of science, how science and scientists work, and the relationship between science and society (Herman, 2015; McComas et al., 1998). Sociocultural factors such as ideologies, identity, socioeconomic situation, religion, and gender (Herman 2013, 2015; Allchin, 2011, 2012; Hodson, 2009; Kahan, 2013, 2015; Kahan et al., 2011; Zeidler, Herman, Ruzek, Linder, \& Lin 2013) also play a role in shaping a worldview that is manifested in beliefs, emotions, thinking, and choices (Herman 2015, 2020, 2021; Cobern, 1993, 1996; Hodson, 2009; Lynch \& McKenna, 1990; Oulton et al., 2004).

Recent scholarship has focused on the complex relationships between peoples' views about science, sociocultural factors, and engagement with science-related topics perceived to be contentious. Nadelson and Hardy (2015) demonstrated that among 159 surveyed undergraduates at a large university, lower levels of evolution acceptance associated with higher levels of religious commitment and distrust of science and scientists, and, to a lesser degree, more conservative political orientations. Author (2015) showed that trust in the validity of the Intergovernmental Panel on Climate Change claims was the foremost positive predictor of secondary marine science students' willingness to mitigate global warming through actions requiring varying levels of 
sacrifice. However, the students' NOS views (e.g., climate science uses a plurality of methods) and sociocultural grouping (e.g., ethnicity and socioeconomic classification) also significantly associated with their willingness to mitigate global warming.

While these myriad factors need not confound reasoned and measured decisionmaking, they can and often do, particularly when misinformation (false information) and disinformation (deliberate dissemination of misleading or biased information) are prevalent regarding science content and how science works. Misinformation and disinformation exacerbate the complexity of SSI, placing all of society at greater risk (NASEM, 2017; Nichols, 2017), but while both are detrimental, disinformation is particularly damaging and dangerous because controversy and doubt is purposely created where it does not belong and perpetuated through public discourse and media, making educative efforts and achieving public confidence far more difficult (Herman, 2013; Harker, 2015).

Furthermore, individuals do not consistently employ epistemological resources and beliefs across the scientific or SSI contexts they encounter (Herman 2015, Bell \& Linn, 2002; Clough \& Herman, 2017; diSessa et al., 2002; Leach et al., 2000; Louca et al., 2004). Sociocultural membership and personal beliefs can erratically bias people's views about the science regarding, and promote or deter action that would assist in addressing, such issues. For instance, Kahan et al. (2011) write about the impact of cultural cognition whereby risk perceptions regarding SSI often become aligned with group members having shared values. Kahan (2013) and Kahan et al. (2012) demonstrate that increased science comprehension increases concern of individuals whose sociocultural identities align with groups accepting climate change. But among individuals who align with groups opposing the scientific consensus on climate change, as their science comprehension increases, they can become more skeptical because they use their greater science proficiency to seek fault with climate change evidence and choose to foreground any conceivable counter-evidence that fits their group's position.

Moreover, the more polarizing an SSI appears to individuals, the more they draw from sociocultural identity and personal reasoning to confirm their beliefs and express acceptance or rejection on such issues. This phenomenon appears to diminish when people encounter ideas that are not perceived as uncertain and perhaps controversial (Kahan, 2015). For instance, Kahan et al. (2011) surveyed members of the US public investigating the magnitude of the relationship between peoples' cultural values and their perceptions of the scientific consensus and the credibility and trustworthiness of experts regarding three controversial issues. They determined that the disparities occurring between the culturally defined groups' perceptions of the scientific consensus and trustworthiness of experts were the largest regarding global warming, lesser with handgun regulation, and lesser still with nuclear waste disposal, illustrating that the level of perceived political polarization on an issue is related to trust. Lewandowsky et al. (2013) surveyed members of the US public and reported that rejection of climate science is strongly predicted by holding self-identified conservatism and free-market economic ideologies. However, conservatism weakly positively and freemarket worldview weakly negatively associated with vaccine acceptance, and both of these ideological positions were not associated with acceptance of genetically modified foods. These reviewed studies demonstrate that sociocultural factors are associated with SSI thinking and engagement. Media messaging and use appears to encourage peoples' socioculturally derived biases in regard to contentious SSI, thus further splintering how groups holding diverse ideologies respond to those issues (Herman, 2013; Barzilai \& Chinn, 2020; Chinn et al., 2021, Feldman et al., 2012). 


\section{Study Purpose and Research Questions}

This study investigated how factors well beyond scientific knowledge and beliefs may play important roles in COVID-19 thinking and decision-making. While it has been noted by scholars (e.g., Herman, 2018) that many studies address SSI that are more abstract and distant (time as well as place) from study participants, the study reported here focuses on participants' thinking and actions in the midst of a health crisis where hospitals in the state were being overrun with COVID-19 cases and lives were lost. Even when personal and societal stakes were undeniably high, factors other than a rational assessment of scientific knowledge may have played a large role in thinking and action in response to the pandemic - even among those who possess science credentials exceeding that of most citizens.

On December 31st, 2019, a pneumonia-like illness in the city of Wuhan, China, first came to the attention of the World Health Organization (WHO, 2020a). The cause was soon identified as a novel coronavirus, named severe acute respiratory syndrome coronavirus 2 (SARS-CoV-2), and the disease it caused was named COVID-19 (WHO, 2020b). Scientists around the world raced to learn more about the virus - its transmission, likely spread, symptoms, disease state, risk factors, how those who contracted the disease could be treated, and how the spread of the virus could be slowed. Policymakers and the public sought immediate projections and answers, expecting science certainty, but instead were faced with science-in-the-making (Latour, 1987) — emerging and tentative research findings, a variety of probabilistic models with differing projections, and cautious, conflicting, and changing implications for action.

The COVID-19 pandemic presented a time-sensitive and unique need to investigate citizen's thinking, emotions, and actions in regard to science-in-the-making that impact personal and societal welfare. Data collected in the midst of a developing SSI has greater validity because it more assuredly reflects genuine thinking and actions at the time, as opposed to how people recall or project their thinking and action outside the occurrence of those issues (Herman, 2018). Data collected long after events have passed are often very unreliable reports of actual thinking and action at the time of the event (Fagerlin et al., 2005; Kormos \& Gifford, 2014). Furthermore, research to understand how sociocultural identity and perceptions about the nature and validity of science may relate to people's risk perceptions and decision-making regarding SSI holds importance for helping educate and better prepare people to more effectively tackle such issues. Reflecting this time-sensitive opportunity, the purpose of the study reported here was to determine whether relationships exist between the group membership, and COVID-19 thinking, and action of post-secondary biology students during spring 2020 while in the midst of the COVID-19 pandemic.

During spring and summer 2020, policymakers and citizens were grappling with a steady stream of science research findings and health officials' recommendations regarding the COVID-19 pandemic. In the midst of this authentic SSI, we sought to answer the following research questions that broadly addressed factors associated with study participants' COVID-19 mitigating personal behaviors (research question 1) and expressed views on societal level COVID-19 mitigating policy proposals (research question 2).

Research question 1 (RQ1) - Factors associated with COVID-19 mitigating personal behavior.

RQ1a: Which of the following factors associate most strongly with university biology students' COVID-19-related behaviors after government imposed stay-at-home orders: (a) political orientation; (b) gender; (c) beliefs about the veracity of COVID-19 claims; 
(d) trust in prominent politicians (e.g., The President of the United States) and health science/medical experts (e.g., World Health Organization) as sources of COVID-19 information; and/or (e) trust in science and scientific modeling to ensure efficacious COVID-19 response?

RQ1b: How does political orientation moderate reliance on science and trust in scientific models and health science/medical experts as sources of information for COVID-19 response when predicting university biology students' COVID-19-related behaviors?

Research question 2 (RQ2) — Factors associated with views on COVID-19 mitigating policy proposals.

RQ2a: Which of the following factors associate most strongly with university biology students' support for future societal COVID-19 responses: (a) political orientation; (b) gender; (c) beliefs about the veracity of COVID-19 claims; (d) trust in prominent politicians and health science/medical experts' as sources of COVID-19 information; and (e) trust in science and scientific modeling to ensure efficacious COVID-19 response?

RQ2b: How does political orientation moderate reliance on science and trust in scientific models and health science/medical experts as sources of information for COVID response when predicting university biology students' support for societal COVID-19 responses?

\section{Study Context and Methodology}

\subsection{Study Context}

The study took place near the end of the spring 2020 semester at a large Texas post-secondary school in three undergraduate introductory biology courses that had included instruction on pathogens and viruses. Beyond the international and national COVID-19 scene, Table 1 lists noteworthy COVID-19-related incidents study participants experienced during spring 2020 semester, illustrating they were in the midst of an important and ongoing SSI.

\subsection{Study Population and Sampling}

The on-line survey, named the COVID-19 Perceptions and Action Survey (CPAS), was made available from April 21st to May 5th through Qualtrics via an anonymous link to 1,420 undergraduate students enrolled across the three biology courses. A total of 797 (56\%) students responded to the survey. Of these, 87 were incomplete or completed in fewer than 8 min which, according to pilot testing, was not sufficient time for serious consideration of the survey items. Thus, $710(50 \%)$ of the broader population of students who were invited to complete the CPAS did so, which falls well within $60 \pm 20 \%$ response and retention rate that is recommended for educational studies (Baruch, 1999).

The CPAS deliberately asked study participants about their behaviors and rationale for those behaviors during the 2 weeks following the state's March 31 stay-at-home order, as this order was the most significant pandemic-related societal event to date. Because surveys were completed from April 21 to May 5, participants' thinking at the time of completing the CPAS may have changed from their thinking during the 2 weeks following the 
Table 1 COVID-19 pandemic events experienced by study participants and their communities

Date Happening

03/12 University cancels classes from 3/16 to 20. All classes held on-line for the remainder of semester.

03/19 Texas Governor issues a public health disaster decree for the state of Texas. This order prohibits groups of more than 10 people and shuts down gyms and bars.

03/26 Texas Governor mandates people flying to Texas from Connecticut, New Jersey, New York, and Louisiana, self-quarantine for 14 days.

03/31 Texas Governor issues order requiring anyone who is not considered an essential and critical worker to stay home (shelter in place) except for essential activity. This coincided with President Trump warning of between 100,000 and 240,000 deaths even if Americans follow the strict social distancing guidelines.

04/17 Texas Governor, citing "semi-flattened" COVID-19 curve, announces plan to reopen the Texas economy. The reopening permits state parks to open on 4/20 under social distancing guidelines, some nonessential surgeries at hospitals to resume starting $4 / 21$, and pickup of goods at retail stores starting 4/24.

04/27 Texas Governor announces phased reopening of the Texas economy beginning 5/1. Phase 1 permits retail stores, restaurants, movie theaters, shopping malls, libraries, and museums to operate at $25 \%$ capacity.

March 31 stay-at-home order. To address this very unlikely issue, we had CPAS respondents review the Institute for Health Metrics and Evaluation (IHME, www.healthdata.org) projections appearing in Fig. 1, and then — on a slider scale ranging from "An extreme under-reaction" through "Just about right" to "An extreme overreaction" — assess the appropriateness of their personal COVID-19 mitigation actions during the 2 weeks after the March 31st stay-at-home order.

A total of 557 study participants responded that, in light of these projections, their COVID-19 actions were appropriate $(M=50$, S.D. $=3.7$ on a 100 -point scale). Thus, we can assume that the students would not have made different COVID-19-related choices

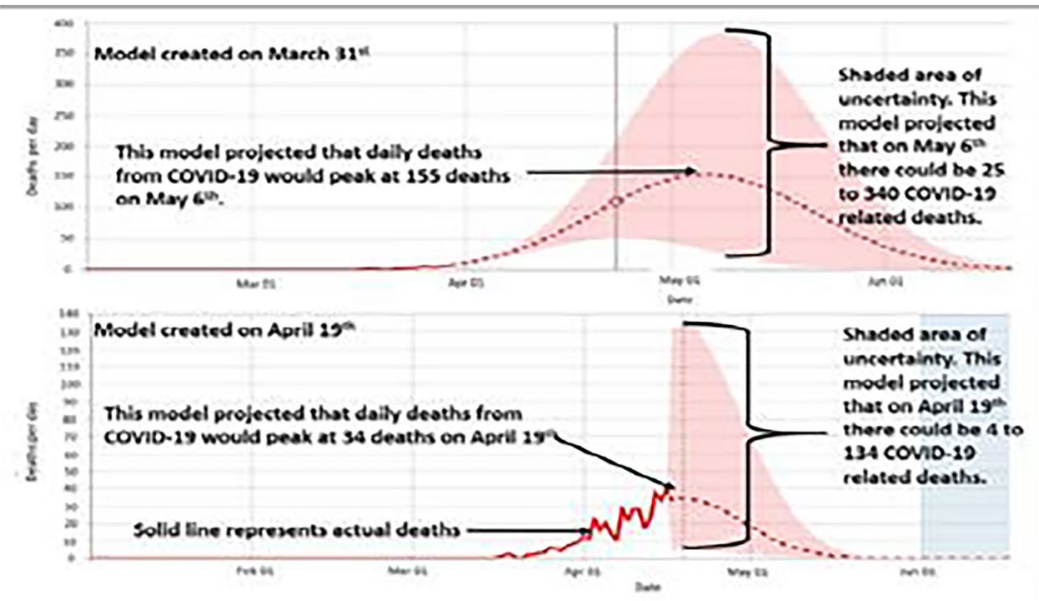

Fig. 1 March 31 and April 19 IHME models showing trajectory Texas COVID-19 fatalities 
during the time period from March 31st to April 14th with the knowledge and beliefs they possessed when completing the CPAS from April 21st to May 5th. This, in turn, permits assessing the relationships between the 557 students' (412 females and 145 males, aged 17 to 37 years, $\bar{x}=19.2$, S.D. $=1.4$ ) science knowledge and beliefs expressed during the data collection period and their reported retrospective COVID-19 actions from March 31 to April 15.

\subsection{Survey Construction, Validity, and Reliability}

The CPAS included single forced-choice items with a 100-point slider response scale that asked students about their trust in health science/medical experts' (e.g., the World Health Organization (WHO), National Institute of Allergy and Infectious Diseases director Fauci) statements; trust in U.S. President Trump's statements about COVID-19 and associated policies; trust in the Texas Governor's statements about COVID-19 and associated policies; the appropriateness of their COVID-19-related actions during the 2 weeks after the government imposed lockdown on March 31st; and their personal political orientation. The participants were also asked to respond to collections of items about more complex topics that included perceptions regarding the veracity of WHO and the Centers for Disease Control (CDC) claims about COVID-19 infection, spread, and misinformation and disinformation; personal trust in science and scientific models to guide COVID-19 response (i.e., decision-making and policy); personal COVID-19 mitigating behaviors (e.g., wearing personal protective equipment in public and social distancing) after the Texas government imposed stay-at-home orders on March 31st; and personal support for societal level COVID-19 policy and response (e.g., social distancing as an ethical commitment and not permitting large social gathering events where infection risk is high). The 100-point slider scales displayed anchor points and approximated an interval scale that enables both the development of constructs comprised of multiple items and the judicious analysis of straightforward single items through parametric approaches (Allen \& Seaman, 2007; Bishop \& Herron, 2015; Carifio \& Perla 2008, Norman, 2010; Vickers, 1999). Tables 2 through 7 provide all CPAS dimensions, items, and slider scale anchor points.

\subsubsection{CPAS Development}

CPAS development occurred over several iterative steps informed by feedback from biology and science education faculty and PhD students, including those specializing in NOS and SSI research, and pilot survey responses from undergraduate biology students (Bennett, 2001; Osborne et al., 2003). The first two authors (having over 40 years of combined NOS and SSI scholarship, teaching experience, and familiarity with the target population) collaboratively drew from existing research and literature regarding NOS, SSI, pseudoscience, risk analysis, COVID-19 information, and misinformation (e.g., Allchin, 2011; Herman, 2015, 2018; CDC, 2020; Harker, 2015; Hodson, 2009; WHO 2020a, b, c; Wong et al., 2008) to write initial prompts aligned to this study's research questions. The authors then independently completed and reviewed the survey in order to evaluate its clarity and content validity; followed by meeting and revising the survey. The survey was then sent to three science education faculty and two practicing biology teachers to complete and feedback regarding the survey's clarity and content validity. Based on this feedback, the survey was revised and then piloted with 37 undergraduate biology students, similar to those in the study reported here. One student indicated that two questions caused a little confusion 
Table 2 Examples of single-response CPAS slider-scale items with anchor points

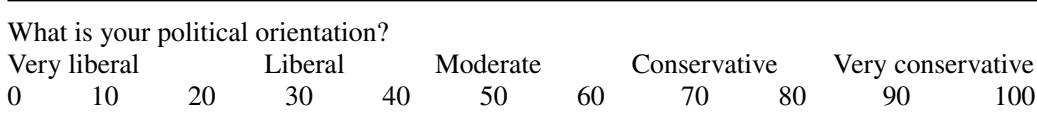

President Trump's statements about COVID-19 and how to respond to it are accurate and trustworthy.

Not at all About half of the time Always

$\begin{array}{llllllllll}0 & 10 & 20 & 30 & 40 & 50 & 60 & 70 & 80 & 90\end{array}$

Governor Abbot's statements about COVID-19 and how to respond to it are accurate and trustworthy.

Not at all About half of the time

Always

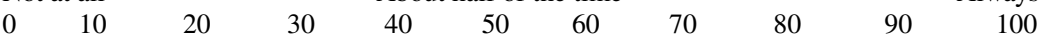

The health science/medical experts' (e.g., the World Health Organization (WHO), National Institute of Allergy and Infectious Diseases director Fauci) statements about COVID-19 and how to respond to it are accurate and trustworthy.

Not at all

$\begin{array}{llllllllll}0 & 10 & 20 & 30 & 40 & 50 & 60 & 70 & 80 & 90\end{array}$

After reviewing IHME projections (see Fig. 1), I think my personal actions in response to COVID-19 after March 31st lockdown were:

An extreme under-reaction Just about right An extreme overreaction

$\begin{array}{llllllllll}0 & 10 & 20 & 30 & 40 & 50 & 60 & 70 & 80 & 90\end{array}$

because of their similarity, 27 overtly stated that none of the pilot survey questions were confusing, and the remaining 9 did not respond to this question. Reliability and validity analyses conducted on pilot data demonstrated Cronbach's alphas and mean inter-item correlations on collections of items intended to serve collectively as constructs respectively range from 0.32 to 0.85 and 0.20 to 0.46 . Mean inter-item correlations are emphasized here with a minimum threshold of 0.15 because they provide better estimates of internal consistency than Cronbach's alpha when scales consist of fewer than ten items (see Briggs \& Cheek, 1986; Clark \& Watson, 1995). Thus, satisfactory internal consistency existed among the piloted item responses (Table 3). A final round of survey revisions for comprehensibility and validity was then conducted and also included adding four items measuring support for societal level COVID-19 policy and response. The validity and reliability of these items, and all CPAS items as scales established with the full CPAS administration are discussed below.

\subsubsection{CPAS Scales Establishment, Validity, and Reliability}

Principle components analyses (PCA) (Tabachnick \& Fidell, 2007) with Direct Oblimin rotation were conducted on the 557 students' responses to items measuring the veracity of various COVID-19 claims (11 items); reliance on science and trust in scientific models to guide COVID-19 response (9 items); COVID-19 mitigating behaviors after the Texas government imposed stay-at-home orders on March 31st (6 items); and support for societal level COVID-19 policy and response (4 items). PCA factors were retained and scales established based on Kaiser's criterion with eigenvalues $>1$, parsimoniously explaining $\geq 0.50$ total variance, and Catell's scree test (Beavers et al., 2013; Streiner, 1994; Tabachnick $\&$ Fidell 2007). Pattern and structure matrices were analyzed to attribute items to factors on which they loaded (minimum factor loading $\geq 0.40$ ) the most significantly. Items with low factor loadings $(<0.40)$ and/or communalities $(0.30)$ were inspected for possible removal. Cronbach's alpha and mean inter-item correlation for each subset of items representing extracted factors were calculated and reported with optimal mean inter-item correlations 


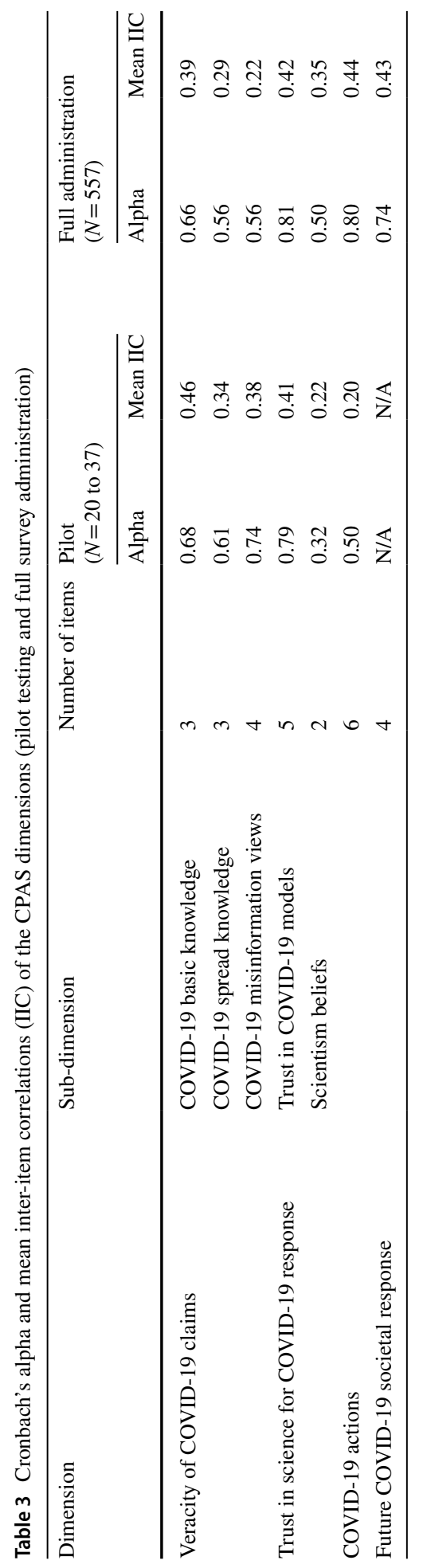


ranges from 0.15 to 0.50 indicating satisfactory internal consistency. Constructs of collective items were summed, averaged, and normalized on a 100-point scale. Details regarding the establishment of scales through PCA and internal consistency analyses appear below.

\subsubsection{CPAS Items Addressing Veracity of COVID-19 Claims}

Students' responses to 11 items based on WHO and CDC position statements about COVID-19 infection, spread, and misinformation and disinformation were analyzed through PCA. The data demonstrated suitability for PCA with several items being sufficiently correlated ( $\geq 0.30$ ), Kaiser-Meyer-Oklin value of 0.73 that exceeds the minimum of 0.60, and a significant Bartlett's Test of Sphericity. PCA demonstrated three components with eigenvalues exceeding 1 and respectively explaining $24.8 \%, 14.4 \%$, and $10.2 \%$ of the variance. Screeplot inspection supported retaining a three-component solution. However, one item, Antibiotics are effective in treating COVID-19, demonstrated a low communality (0.28) and was removed.

The final three-component solution explained a total of $52.9 \%$ of the variance. Components 1,2, and 3 respectively contributed $26.5 \%, 15.3 \%$, and $11.1 \%$ of the variance. Oblimin rotation revealed a simple structure and all but one item (Some people may develop more severe health complications from COVID-19) substantially loaded on only one of the three components. After inspecting the remaining item that loaded on two components, that item was grouped on the component it loaded most strongly and that included conceptually similar items. Interpretation of each of the three components (i.e., sub-dimensions) entailed establishing the common theme among each component's items. Based on this interpretation, component 1 represents COVID-19 spread prevention knowledge, component 2 represents COVID-19 misinformation/disinformation beliefs, and component 3 represents COVID-19 basic knowledge (Table 4). The mean inter-item correlations for each of the three sub-dimensions of items exceeded 0.15 , thus indicating satisfactory internal consistency (Table 3). Again, the scores for students' responses to the items for each of the three sub-dimensions were summed, averaged, and normalized on a 100-point scale. For ease of interpretation through regression analyses, the summed and averaged score for component 2, which were comprised of reverse coded COVID-19 misinformation and disinformation beliefs, was then subtracted by 100 . Thus, higher scores were consistent with stronger beliefs that COVID-19 misinformation and disinformation claims hold veracity.

\subsubsection{CPAS Items Addressing Reliance on Science and Trust in COVID-19 Models for Pandemic Response}

Three items asked students about their reliance on science to resolve the COVID-19 pandemic. Six items asked students about their trust in scientific models, after reviewing Fig. 1, to guide COVID-19 response, policy, and decision-making. Collectively, these items demonstrated appropriateness for PCA with multiple items being substantially correlated $(\geq 0.30)$, a Kaiser-Meyer-Oklin value of 0.81 , and a significant Bartlett's Test of Sphericity. Two components demonstrated eigenvalues exceeding 1 and respectively explained $38.6 \%$ and $15.3 \%$ of the variance. Screeplot inspection supported retaining a two-component solution. However, two items, Scientific evidence should be the only consideration used when responding to the COVID-19 pandemic and The models projecting COVID-19 mortality rates are just scientists' guesses, were removed. The former demonstrated correlations with 
宊

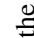

当

:

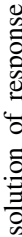

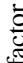

$\stackrel{\mathscr{0}}{\Xi}$

4

.

吉

호요

즐

胃

范 :

空

妾
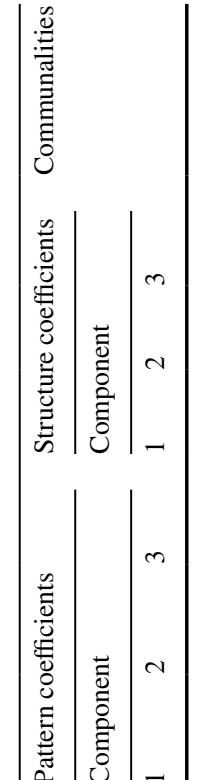

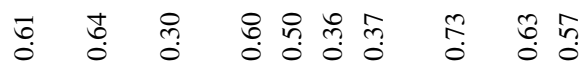

$=$ ป

ํㅏㅇ

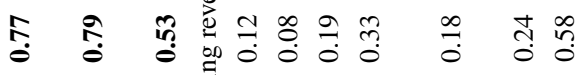

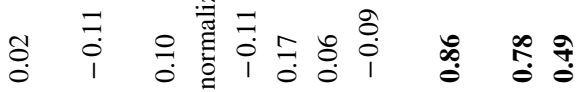

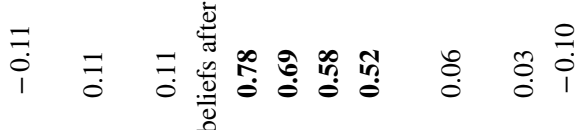

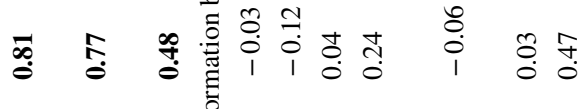

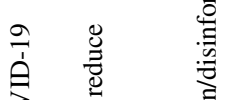

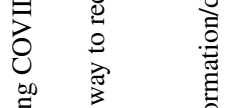

$\stackrel{0}{=}$

.

要

ำ

焉

है क्षे

产 吾

8

는

:

$\infty$

8

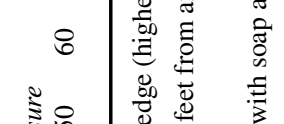

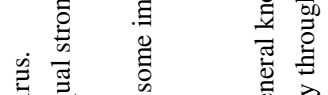

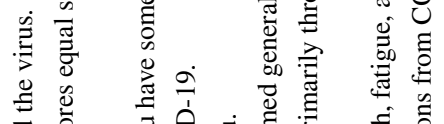

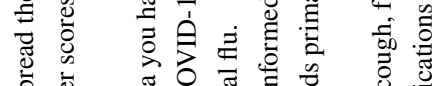

के 劳

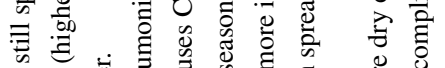

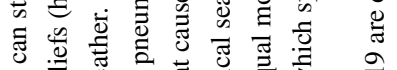

ฮั

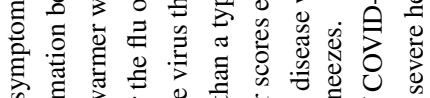

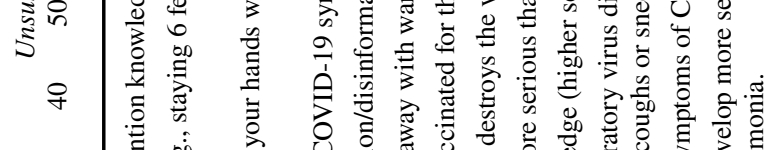

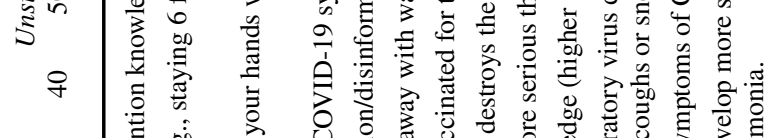

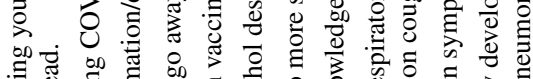

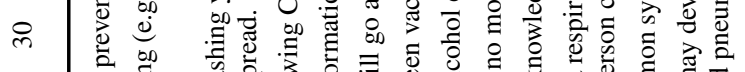

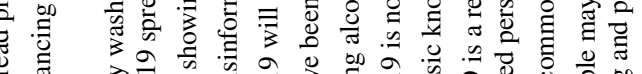

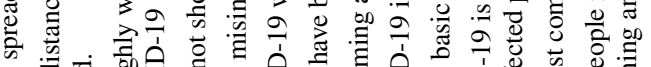

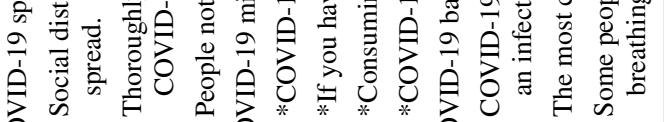

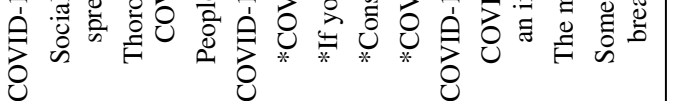


all other items in the PCA that were much lower than 0.30, and the latter a low communality (0.27).

The final two-component solution explained a total of $63.4 \%$ of the variance, with components 1 and 2 respectively contributing $45.4 \%$ and $17.9 \%$ of the variance. Oblimin rotation revealed a simple structure with all items substantially loading on one of the two components. Component 1 was interpreted to represent trust in COVID-19 models for pandemic decisions and responses, whereas component 2 included items that appear to gauge a kind of scientism perspective - an over confidence that science and technology alone, sans personal action, will resolve the COVID-19 pandemic. The mean inter-item correlations for each of the two sub-dimensions of items exceeded 0.15 , thus indicating satisfactory internal consistency (Table 3). Again, the scores for students' responses to the items for each of the two sub-dimensions were then summed, averaged, and normalized on a 100 -point scale. Table 5 provides the score descriptions and items used for each of the two sub-dimensions of the trust in science for COVID-19 response.

\subsubsection{CPAS Items Addressing COVID-19 Personal Mitigating Actions}

COVID-19 mitigating behaviors after the Texas government imposed stay-at-home orders on March 31st were addressed through 6 items. The data demonstrated appropriateness for PCA with multiple items being substantially correlated $(\geq 0.30)$, a Kaiser-Meyer-Oklin value of 0.79 , and a significant Bartlett's Test of Sphericity. PCA demonstrated a unidimensional solution with one component with an eigenvalue of 3.041 that explained $50.7 \%$ of the variance. Screeplot inspection supported a unidimensional solution. Because all items loaded on a single component, Oblimin rotation did not occur. All communalities were substantially higher than 0.3 and the mean inter-item correlation for this set of items exceeded 0.15 indicating satisfactory internal consistency (Tables 3 and 6). The scores for students' responses to each of the COVID-19 action items were then summed, averaged, and normalized on a 100-point scale. Table 6 provides the score description for this dimension.

\subsubsection{CPAS Items Addressing Future COVID-19 Societal Response}

Support for various future societal level COVID-19 responses was addressed in 4 items. The data demonstrated appropriateness for PCA with multiple items being substantially correlated ( $\geq 0.30$ ), a Kaiser-Meyer-Oklin value of 0.76 , and a significant Bartlett's Test of Sphericity. PCA demonstrated a unidimensional solution with one component having an eigenvalue of 2.284 that explained $57.1 \%$ of the variance. Screeplot inspection supported a unidimensional solution. Because all items loaded on a single component, Oblimin rotation did not occur. All communalities were substantially higher than 0.3 and the mean interitem correlation for this set of items exceeded 0.15 indicating satisfactory internal consistency (Tables 3 and 7). The scores for students' responses to each of the future societal COVID-19 response items were then summed and normalized on a 100-point scale.

\subsection{Data Analyses}

Hierarchical moderated multiple regression was used to control for the day on which the CPAS was completed and investigate: (1) the extent that university biology students' COVID-19-related behaviors after government imposed stay-at-home orders 


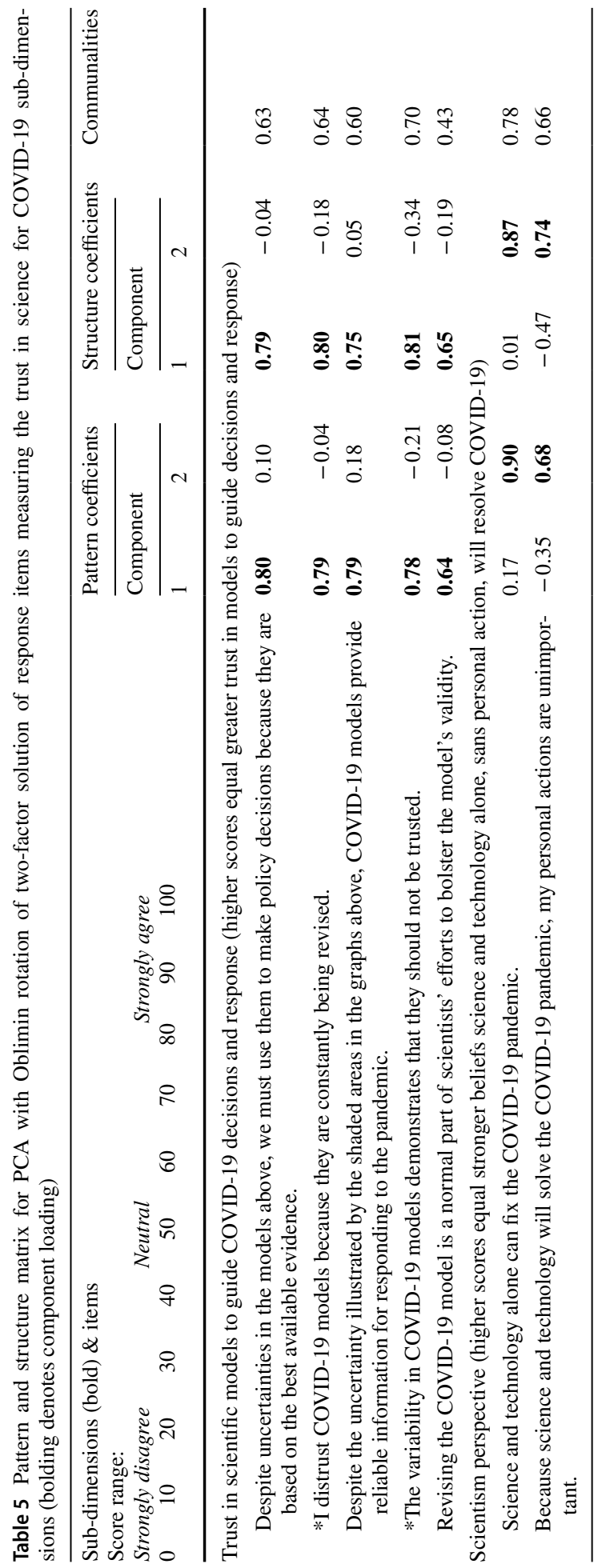


Table 6 Communalities of COVID-19 action items

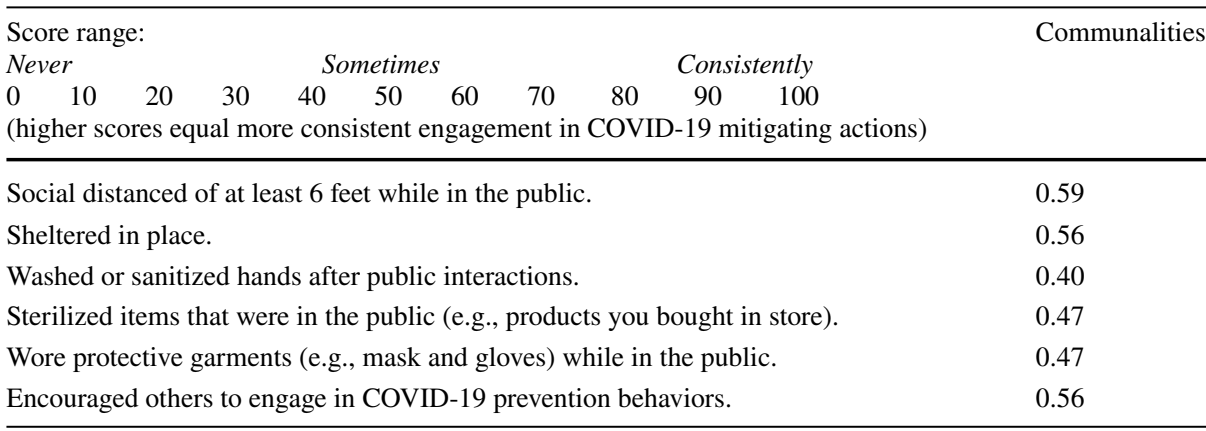

Table 7 Communalities of future societal COVID-19 response items

\begin{tabular}{|c|c|}
\hline 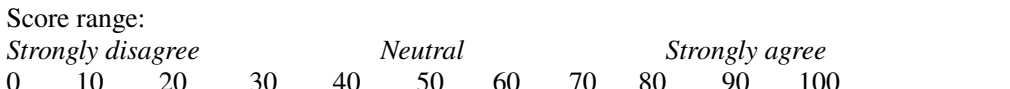 & Communalities \\
\hline (higher scores equal stronger support for societal level COVID-19 mitigating res & \\
\hline $\begin{array}{l}* \text { Public events should be permitted with individuals deciding for themselves whether they } \\
\text { wish to risk COVID-19 infection. }\end{array}$ & 0.67 \\
\hline *In person college and high school graduation ceremonies should be permitted this May. & 0.60 \\
\hline Those who do not appropriately social distance are acting in an unethica & 0.54 \\
\hline $\begin{array}{l}\text { If college and professional football seasons occur this fall, fans should not be permitted to } \\
\text { attend. }\end{array}$ & 0.48 \\
\hline
\end{tabular}

*Reverse coded

are associated with: (a) political orientation; (b) gender; (c) beliefs in the veracity of COVID-19 claims; (d) perceptions of the trustworthiness and accuracy of prominent sources (e.g., health science/medical experts) of COVID-19 information and guidance; and (e) reliance on science and trust in scientific models for COVID-19 response; and (2) whether political orientation moderates the relationship between the students' engagement in COVID-19 actions and their reliance on science and trust in health science/medical experts and science models for COVID-19 response. Hierarchical moderated multiple regression was also used to investigate the extent that university biology students' support for future societal COVID-19 responses was predicted by the same set of variables after controlling for the day on which the survey was completed. The use of hierarchical moderated multiple regression analyses to control for the day the students completed the CPAS is warranted given the rapidly evolving nature of the pandemic on a personal and societal level, and that we wanted to ensure that the participants' responses did not vary over the 2 weeks the survey was available. While methodologists sometimes recommend centralizing regressor variables involved in moderated multiple regression, we followed procedures outlined by Kromrey and Foster-Johnson (1998) who successfully demonstrate such recommendations are specious and that centering regressor variables is unnecessary, results in no benefit gained regarding minimizing multicollinearity, and does not change regression results. 


\section{Results}

The means, standard deviations, skewness and kurtosis, and correlations of the variables used in this study are reported in Tables 8 and 9. Preliminary analyses were conducted prior to both regressions to screen for violations of normality, linearity, multicollinearity, and homoscedacity. Skewness and kurtosis values indicate that the score distributions for each variable approximated normality and were appropriate for parametric analyses - particularly given the large sample size (>300) included in this study (Kline, 2016; Tabachnick \& Fidell, 2007). Inspection of normal probability plots and regression standardized residual scatterplots demonstrated acceptable linearity and homoscedacity. All variance inflation factor $(\mathrm{VIF})<10$, and tolerance indicators of multicollinearity were within acceptable ranges ( $\mathrm{VIF}<10$, tolerance $>0.10$ ) across the two regressions, with the exception of those involved in tests for interactions. Again, elevated VIF in these cases is expected and non-concerning (Kromrey \& Foster-Johnson, 1998). However, inspection of the correlation matrix indicated the correlations between an increasingly conservative political orientation and perceptions of the trustworthiness of President Trump's and Governor Abbot's statements about COVID were highly and significantly correlated (Table 9). These results make theoretical sense given that President Trump and Governor Abbot are considered to be strongly conservative and oftentimes polarizing political figures. Therefore, among these three independent variables, only political orientation was retained in the regression models as it most likely encompasses the participants' perceptions of trustworthiness of President Trump and Governor Abbot.

Table 9 presents the Pearson correlations between all variables used in this investigation. Pearson correlation analysis demonstrated significant, yet weakly negative, associations between the day the students completed the CPAS and increasingly conservative political orientation and perceptions of trustworthiness of President Trump's and Governor Abbott's COVID-19 guidance ( $r=-0.14$ to -0.17$)$. A weakly positive correlation existed between the day of CPAS completion and trust in scientific model projections $(r=0.11)$. The extent that students engaged in COVID-19 mitigating actions after the March 31st government imposed lockdown and their support societal level COVID-19 mitigating response in the future demonstrated a significantly and moderately large positive correlation $(r=0.43)$.

Correlation analysis demonstrated significant, yet weakly negative, associations between the students' gender and the extent they believed that their personal actions are unimportant given science and technology alone will resolve the pandemic, with males appearing to be slightly more likely to assume these views $(r=-0.13)$. Weakly positive correlations occurred between the students' gender and their trust in health science/medical experts' (e.g., WHO, $r=0.10$ ) statements and engagement in COVID-19 mitigating actions $(r=0.18)$, with females appearing to score higher on these measures.

Significant and largely positive correlations occurred between an increasingly conservative political orientation score and increased trust in President Trump's and Governor Abbott's COVID-19 guidance ( $r=0.51$ to 0.70 ). Increasingly conservative political orientation scores and higher levels of trust in the accuracy President Trump's COVID-19 guidance were significantly and modestly correlated with increasing beliefs in the veracity of COVID-19 misinformation $(r=0.26$ to 0.29$)$. Students' increasingly conservative political orientation and higher levels of trust in President Trump's COVID-19 guidance were also similarly and negatively associated, from a small to moderately large extent, with their knowledge about how COVID-19 spreads $(r=-0.14)$, trust in health science/medical experts' (e.g., WHO, $r=-0.11$ to -0.13 ) statements and scientific models $(r=-0.24$ 


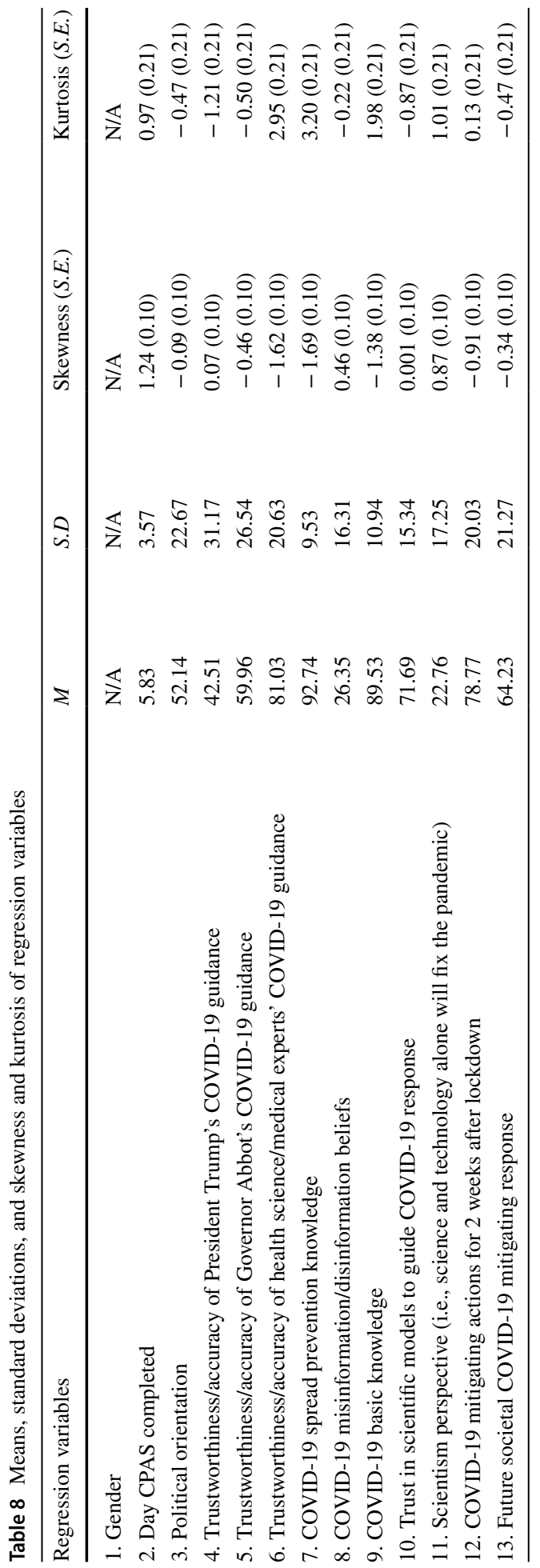




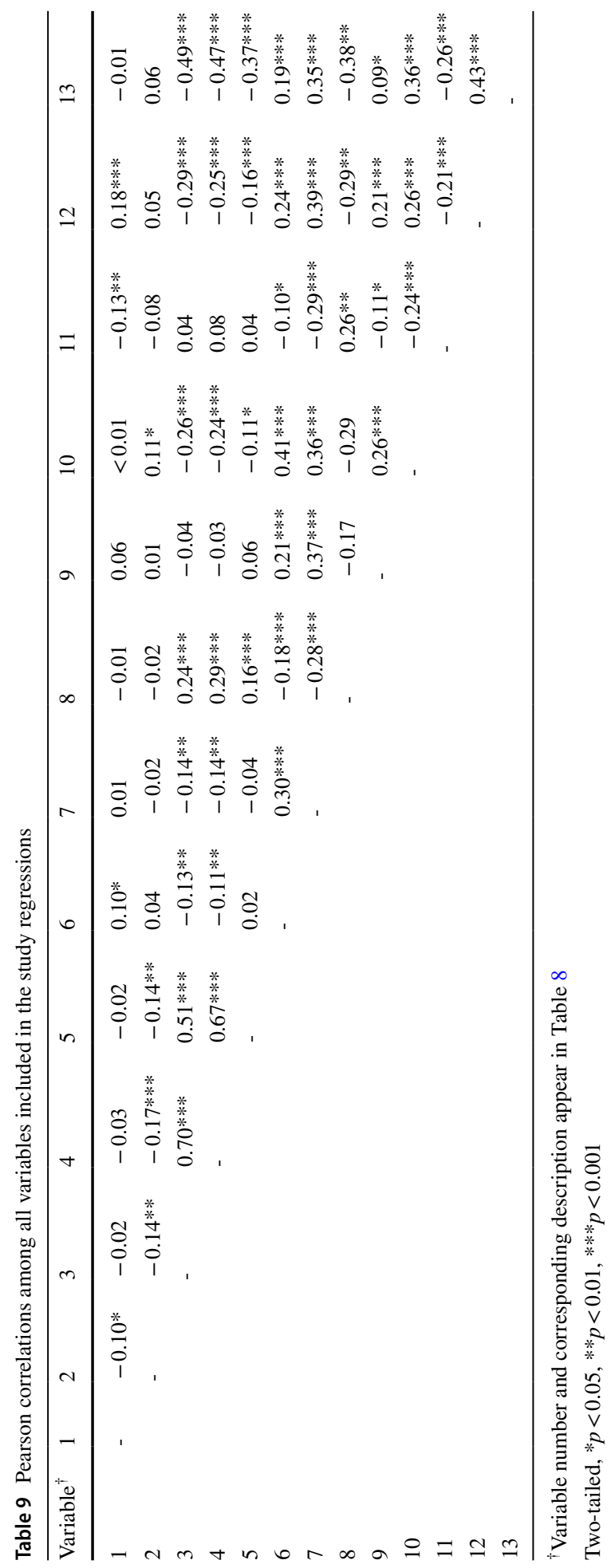


to -0.26$)$ to guide COVID-19 pandemic response, engagement in COVID-19 mitigating actions ( $r=-0.25$ to -0.29 ), and support for societal level COVID-19 mitigating response going forward ( $r=-0.47$ to -0.49 ). Students' trust in the accuracy of Governor Abbott's response was weakly positively correlated with increasing beliefs in the veracity of COVID-19 misinformation ( $r=0.16$ ), and weakly to moderately negatively correlated with trust scientific models $(r=-0.11)$ to guide COVID-19 pandemic response, engagement in COVID-19 mitigating actions $(r=-0.16)$, and support for societal level COVID-19 mitigating response in the future $(r=-0.37)$.

The students' increasing trust in health science/medical experts' as sources of information and trust for scientific models for COVID-19 decision-making were moderately and significantly correlated $(r=0.41)$. These variables were also significantly and modestly to moderately positively correlated with the students' COVID-19 spread knowledge $(r=0.30$ to 0.36 ), COVID-19 basic knowledge ( $r=0.21$ to 0.26), engagement in COVID-19 mitigating actions ( $r=0.24$ to 0.26 ), and support for societal level COVID-19 mitigating response going forward ( $r=0.19$ to 0.36 ). Students' increasing trust in health science/medical experts' and their organizations' guidance and trust for scientific models to guide pandemic decision-making, however, were negatively correlated from small to modest degrees with increasing beliefs that COVID-19 misinformation is true $(r=-0.18$ to -0.29$)$ and beliefs that science and technology alone will resolve the pandemic (i.e., scientism, $r=-0.10$ to -0.29 ).

A significant moderately positive correlation occurred between the students' level of COVID-19 basic and spread knowledge $(r=0.37)$. These two forms of knowledge were modestly and negatively correlated with increasing beliefs in the truth of COVID-19 misinformation $(r=-0.17$ to -0.28$)$. Weak to moderate positive correlations were demonstrated between the students' increasingly accurate knowledge of COVID-19 spread and their engagement in COVID-19 mitigating actions $(r=0.39)$, and their support for societal level COVID-19 mitigating response going forward $(r=0.35)$. Smaller, yet still significant and positive correlations were shown between the increasing accuracy of the students' basic COVID-19 knowledge and their engagement in COVID-19 mitigating actions $(r=0.09)$, and support for societal level COVID-19 mitigating response going forward $(r=0.21)$. Students' engagement in COVID-19 actions and support for societal level COVID-19 mitigating response were moderately negatively correlated with students' increasing beliefs that COVID-19 misinformation is true $(r=-0.29$ to -0.38$)$.

\subsection{Predictors of Students' COVID-19 Mitigating Actions and Support for Ongoing Societal COVID-19 Mitigating Response}

Again, hierarchical moderated multiple regressions were used to determine the extent that students' (1) COVID-19 mitigating actions during the 2 weeks after a government imposed lockdown and (2) support for ongoing societal COVID-19 mitigating response were predicted by their: (a) political orientation; (b) gender; (c) beliefs in the veracity of COVID-19 claims; (d) perceptions of the trustworthiness and accuracy of prominent health science/ medical experts' and scientific organizations' COVID-19 information and guidance; and (e) reliance on science and trust in scientific models for COVID-19 response. Furthermore, these analyses were used to detect whether the students' political orientation moderated the relationship between their reliance on science and trust in scientific models and sources of health science information for COVID-19 response, and their personal COVID-19 actions and support for future societal COVID-19 mitigating responses. Table 10 presents all 


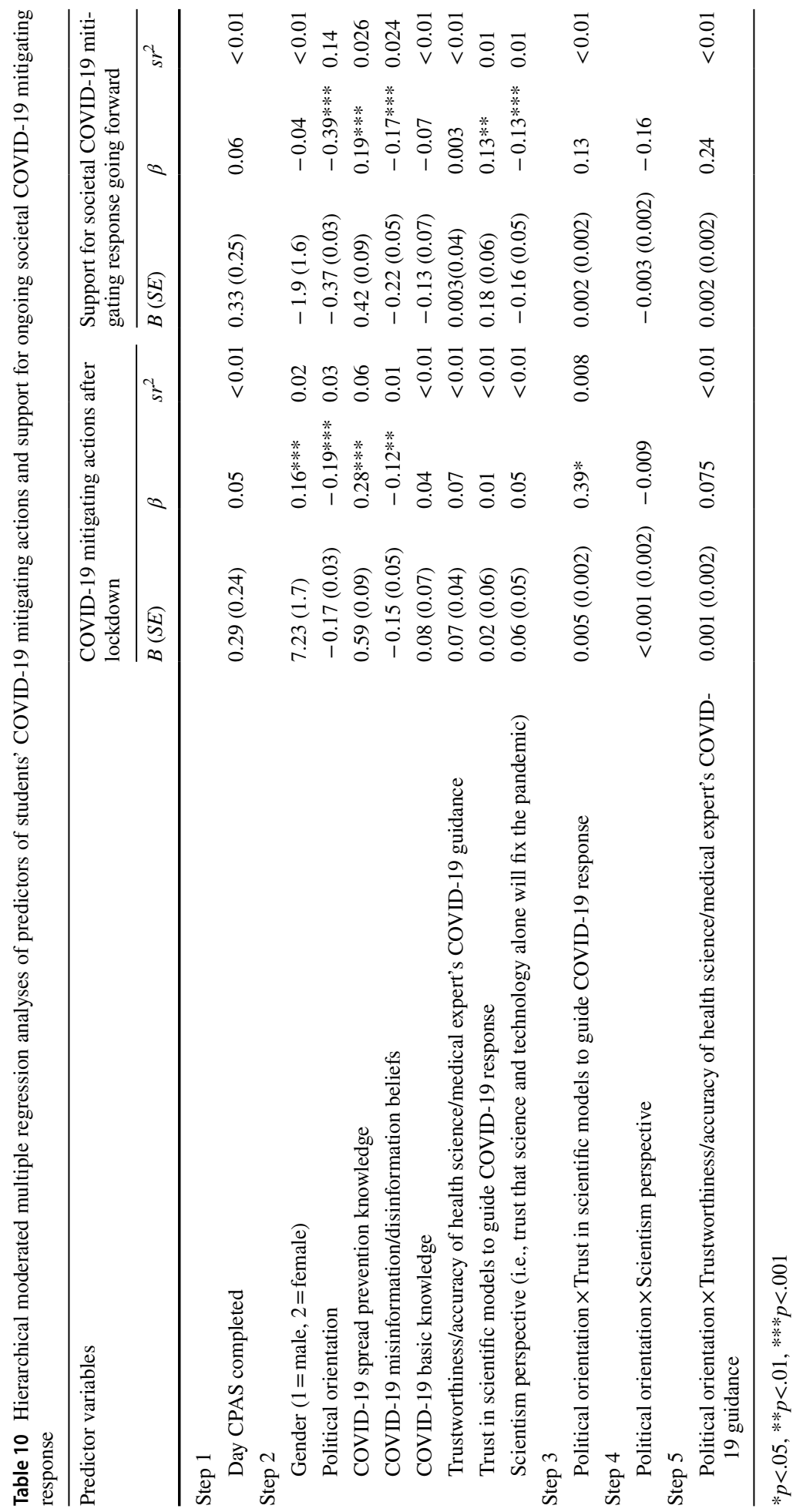


relationships tested through the hierarchical multiple moderated regressions. The results of these analyses are presented below and organized according to this investigation's two research questions. Along with unstandardized $(B)$ and standardized regression $(\beta)$ coefficients, $R^{2}$ values and semi-partial coefficients $\left(s r^{2}\right)$ are also reported. The latter are interpreted as effect sizes where $R^{2}$ and $s r^{2}$ of $0.02,0.13$, and 0.26 . respectively approximate Cohen's (1992) $f^{2}$ of 0.02 (small effect), 0.15 (medium effect), and 0.35 (large effect). Finally, Darlington and Hayes (2017) and Keith (2019) make clear that, holding all other regressors constant, two cases that differ by one standard deviation on a given predictor variable are estimated to differ by $\beta$ standard deviations on the outcome variable. We use these guidelines to provide interpretive statements that demonstrate the estimated magnitude of change in students' COVID-19 mitigating actions and support for societal level COVID-19 mitigating response for one standard deviation of each of the predictor variables that are measured along a 100-point scale, when the other predictor variables are held constant. However, regarding gender, a dummy coded dichotomous variable, the unstandardized coefficient, is interpreted as the difference in male and female students' COVID-19 mitigating actions and support for societal level COVID-19 mitigating response.

\subsubsection{RQ1: Students' COVID-19 Mitigating Actions}

Table 10 shows that step one of the hierarchical moderated multiple regression analysis demonstrated that the extent that the day the students completed the CPAS was not associated with their engagement in COVID-19 mitigating actions during the 2 weeks after the March 31st government imposed lockdown $\left(R^{2}=0.003, F(1,555)=1.51, p=0.22\right)$. After controlling for the day students completed the CPAS, inclusion of all independent variables in step 2 explained an additional $27 \%$ of the variance of the students' engagement in COVID-19 mitigating actions during the 2 weeks succeeding the lockdown $\left(\Delta R^{2}=0.27\right.$, $\Delta F(8,547)=25.5, p<0.001)$. Significant predictors of the students' COVID-19 mitigating actions at step two of the regression, in order of importance, were (1) COVID-19 spread prevention knowledge $(\beta=0.28)$; (2) political orientation $(\beta=-0.19)$; (3) gender $(\beta=0.16)$; and (4) beliefs about COVID-19 misinformation/disinformation $(\beta=-0.12)$. Each of these predictors uniquely explained between 1 and $6 \%$ of the variance in the students' COVID-19 mitigating actions.

More specifically, more informed spread prevention knowledge and being female predicted significantly higher levels of COVID-19 mitigating actions. Based on standardized regression coefficients (Table 10), holding all other regressors constant, and on a 100-point scale, every increase of 9.5 points (one standard deviation) of COVID spread knowledge scores associates with a 5.6-point increase (0.28 standard deviation) in scores measuring COVID-19 mitigating actions after the government stay-at-home orders. Considering unstandardized regression coefficients, females can be expected to score approximately 7.23 points higher than males on that same 100-point scale measuring COVID-19 mitigating actions.

However, lower levels of COVID-19 mitigating actions were significantly predicted by increasing levels of conservative political orientation and beliefs that common COVID19 misinformation and disinformation claims are true. On a 100-point scale and holding all other regressors constant, an increase of a 22.7 points (one standard deviation) on the political orientation scale (e.g., moving from liberal to moderate or moderate to conservative) associates with a reduction of 3.8 points $(-0.19$ standard deviation) in students' levels of COVID-19 mitigating actions, whereas an increase of a 16.3 points (one standard 
Table 11 Means and standard deviations of students', when grouped based on political orientation, trust in scientific models to guide COVID-19 response, and COVID-19 mitigating actions for 2 weeks after stay-athome orders

\begin{tabular}{llllll}
\hline Political orientation & & $\begin{array}{l}\text { Trust in scientific models to } \\
\text { guide COVID-19 response }\end{array}$ & $\begin{array}{l}\text { COVID-19 mitigating } \\
\text { actions for 2 weeks } \\
\text { after stay-at-home } \\
\text { orders }\end{array}$ \\
\cline { 3 - 5 } & $N$ & $M$ & $S . D$ & $M$ & $S . D$ \\
\hline Very liberal & 47 & 76.7 & 14.9 & 87.0 & 16.1 \\
Liberal & 111 & 77.9 & 15.4 & 84.6 & 15.2 \\
Moderate & 172 & 70.8 & 14.7 & 81.2 & 18.8 \\
Conservative & 156 & 70.4 & 14.5 & 72.9 & 20.8 \\
Very conservative & 71 & 63.7 & 14.6 & 71.2 & 24.2 \\
\hline
\end{tabular}

Table 12 Follow-up analyses for each political orientation group regressing their trust in scientific models to guide COVID-19 decision-making and response on engagement of COVID-19 actions after the government stay-at-home orders

\begin{tabular}{lllllll}
\hline Political orientation & $R^{2}$ & $F$ & $p$ & $B(S E)$ & $\beta$ & $s r^{2}$ \\
\hline Very liberal & 0.002 & $0.08(1,45)$ & 0.77 & $0.05(0.16)$ & 0.04 & $<0.01$ \\
Liberal & 0.001 & $0.02(1,109)$ & 0.88 & $0.01(0.09)$ & 0.01 & $<0.01$ \\
Moderate & 0.08 & $13.7(1,170)$ & $<0.001$ & $0.35(0.09)$ & 0.27 & 0.06 \\
Conservative & 0.06 & $9.6(1,154)$ & 0.002 & $0.35(0.11)$ & 0.24 & 0.08 \\
Very conservative & 0.11 & $8.2(1,69)$ & 0.005 & $0.54(0.19)$ & 0.33 & 0.11 \\
\hline
\end{tabular}

deviation) in students' scores measuring their believing COVID-19 misinformation associates with a reduction of 2.4 points $(-0.12$ standard deviation) in students' levels of COVID-19 mitigating actions.

Hierarchical moderated multiple regression analyses at step three demonstrated a significant interaction, which indicated the students' political orientation moderated the relationship between their trust in scientific models to guide COVID-19 decisions and response and their personal COVID-19 actions $\left(\Delta R^{2}=0.007, \Delta F(1,546)=5.5, p<0.02\right)$. To further investigate this relationship, the students were then parsed into five dummy-coded subgroups according to the CPAS anchor points that the students used to self-identify their political orientation (e.g., scores of 80-100 were coded as "very conservative," see Table 2). Then, follow-up regressions and spotlight analyses were conducted to determine how each political orientation subgroup's trust in scientific models to guide COVID-19 decisions and response predicted their engagement of COVID-19 actions after the March 31 st government imposed stay-at-home order.

Table 11 shows that across the five student groups, organized from very liberal to very conservative, a decrease occurs in the mean scores gauging the students' COVID19 mitigating actions and their trust in scientific models to guide COVID-19 response. Table 12 demonstrates that among students identifying as very liberal and liberal, there was no association between trust in scientific models to guide COVID-19 decision-making and response and their conducting COVID-19 actions during the 2 weeks after the March 31st government stay-at-home order (very liberal: $R^{2}=0.002, F(1,45)=0.08$, 
$p=0.73$; liberal: $\left.R^{2}=0.000, F(1,109)=0.02, p=0.89\right)$. Inspection of Fig. 2 shows that the very liberal and liberal students' high levels of COVID-19 actions are irrespective of the extent they trust scientific models to guide COVID-19 decision-making and response. Conversely, respectively across moderate, conservative, and very conservative student groups, trust in scientific models to guide COVID-19 decision-making predicted, to a significant and small to medium extent, their conducting COVID-19 mitigating actions during the 2 weeks after the government stay-at-home orders (moderate: $R^{2}=0.08, F(1,170)=13.7, p<0.001$; conservative: $R^{2}=0.06, F(1,154)=9.6$, $p=0.002$; very conservative: $\left.R^{2}=0.11, F(1,69)=8.2, p=0.005\right)$.

Figure 2 demonstrates that across politically moderate, conservative, and very conservative student groups, an increased trust in the efficacy of scientific models to guide COVID-19 decision-making, despite those models' exhibiting uncertainty and malleability, has a positive impact on the extent students in these groups engage in COVID19 mitigating actions. This is particularly the case for students identifying as very conservative. Trust in scientific models for guiding COVID-19 decision-making alone explained 6 to $8 \%$ of the variance in moderate and conservative students' COVID-19 actions. On a 100-point scale, an increase of 14.7 and 14.5 points (one standard deviation) respectively in moderate and conservative students' trust in models scores associates with an approximately five-point ( 0.24 to 0.27 standard deviation) increase in their scores measuring their COVID-19 mitigating actions. Eleven percent of the variance in very conservative students' COVID-19 actions was explained by the same forms of trust in scientific models. An increase of one standard deviation (14.6 points) of very conservative students' trust in scientific model scores associates with an 8-point $(0.33$ standard deviation) increase in COVID-19 mitigating action scores. None of the remaining tested variables and interactions demonstrated significance.

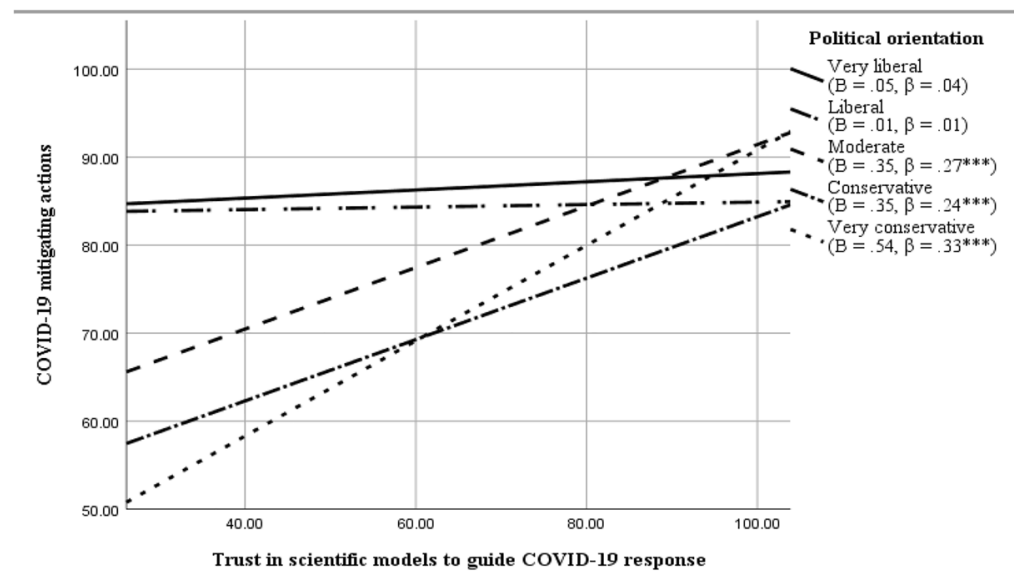

Fig. 2 Regression plotting of different political orientation groups showing the effects of trust in scientific models to guide COVID-19 decision-making and response on engagement of COVID-19 actions after a government imposed stay-at-home order 


\subsubsection{RQ2: Support for Ongoing Societal COVID-19 Mitigating Response}

Step one of the hierarchical moderated multiple regression analysis demonstrated that the extent that the day the students completed the CPAS did not significantly associate with their level of support for societal level COVID-19 mitigating responses (e.g., not permitting in person graduation ceremonies and football games, Table $10 \mathrm{R}^{2}=0.003$, $F(1,555)=1.68, p=0.19)$. After controlling for the day the students completed the CPAS, inclusion of all independent variables in step 2 explained an additional $40 \%$ of the variance in the students' support for societal level COVID-19 mitigating responses $\left(\Delta R^{2}=0.40, \Delta F(8,547)=45.1, p<0.001\right)$. The significant predictors of students' support for societal level COVID-19 mitigating responses, in order of importance, were (1) political orientation $(\beta=-0.39)$; (2) COVID-19 spread prevention knowledge $(\beta=0.19)$; (3) beliefs about COVID-19 misinformation and disinformation $(\beta=-0.17)$; (4) trust in scientific models for guiding COVID-19 decision-making $(\beta=0.13)$; and (5) beliefs that science and technology, sans personal action, alone will fix the pandemic $(\beta=-0.13)$. Political orientation uniquely explained $14 \%$ of the variance in the students' support for societal level COVID-19 mitigating responses going forward. The remaining significant predictors uniquely explained between 1 and $3 \%$ of the variance in the students' support for such COVID-19 responses.

These findings suggest that being increasingly politically conservative, believing common COVID-19 misinformation and disinformation claims, and perceiving that science and technology alone will resolve the COVID-19 pandemic result in lower levels of support for future COVID-19 responses that include social distancing as an ethical commitment and not permitting large social gathering events where infection risk is high. On a 100-point scale and holding all other regressors constant, an increase of 22.7 points (one standard deviation) on the political orientation scale (e.g., moving from liberal to moderate or moderate to conservative) associates with a reduction of 8.3 points ( -0.39 standard deviation) in students' levels of support for societal level COVID-19 responses. An increase of 16.3 points (one standard deviation) in students' scores measuring their beliefs that COVID-19 misinformation/disinformation holds veracity associates with a reduction of 3.6 points $(-0.17$ standard deviation) in their support for the same societal responses. Lastly, increasing students' scores measuring their thinking that science and technology alone will resolve the pandemic, one standard deviation (17.3 points) corresponds with a 2.8-point ( -0.13 standard deviation) decrease in scores measuring support for societal level COVID-19 actions going forward.

However, high levels of support for such COVID-19 mitigating responses are associated with an advanced understanding of how COVID-19 spreads and trust in scientific models to guide COVID-19 decision-making and response. Keeping all regressors constant and on a 100-point scale, increasing COVID-19 spread knowledge scores 9.5 points (one standard deviation) associates with a 4.0-point (0.19 standard deviation) increase in scores measuring students' support for societal level COVID-19 actions going forward. Increasing students' trust in scientific model scores one standard deviation (15.3) corresponds with a 2.8-point (0.13 standard deviation) increase in their support for societal level COVID-19 actions going forward. None of the other tested variables and interactions demonstrated significance (Table 10). 


\section{Summary of Results}

The hierarchical moderated multiple regression analyses demonstrate that scientific knowledge, beliefs, and trust, and sociocultural factors are associated with/appear to influence personal COVID-19 behaviors (research question 1) and views regarding societal level COVID-19 mitigating policy proposals (research question 2). Salient findings appear below and are elaborated upon in "Sect. 8."

RQ1a: Which of the following factors associate most strongly with university biology students' COVID-19-related behaviors after government imposed stay-at-home orders: (a) political orientation; (b) gender; (c) beliefs about the veracity of COVID-19 claims; (d) trust in prominent politicians (e.g., The President of the United States) and health science/medical experts (e.g., World Health Organization) as sources of COVID-19 information; and/or (e) trust in science and scientific modeling to ensure efficacious COVID-19 response?

- In order of importance, significant predictors of the students' COVID-19 mitigating actions were (1) COVID-19 spread prevention knowledge; (2) political orientation; (3) gender; and (4) beliefs about COVID-19 misinformation/disinformation.

- More informed spread prevention knowledge and being female significantly associated with higher levels of COVID-19 mitigating actions.

- Lower levels of COVID-19 mitigating actions were significantly associated with increasing levels of conservative political orientation and beliefs that common COVID-19 misinformation and disinformation claims are true.

- Trust in prominent health science/medical experts as sources of COVID-19 information was not associated with levels of COVID-19 mitigating actions.

RQ1b: How does political orientation moderate reliance on science and trust in scientific models and health science/medical experts as sources of information for COVID-19 response when predicting university biology students' COVID-19-related behaviors?

- The students' political orientation moderated the relationship between their trust in scientific models to guide COVID-19 decisions and their personal COVID-19 actions. Trust in scientific models to guide COVID-19 decision-making was a significant positive predictor of moderate, conservative, and very conservative student groups' COVID-19 mitigating actions. Conversely, there was no association between very liberal and liberal students' trust in scientific models to guide COVID19 decision-making and their conducting COVID-19 actions.

- No other significant interactions were present.

RQ2a. Which of the following factors associate most strongly with university biology students' support for future societal COVID-19 responses: (a) political orientation; (b) gender; (c) beliefs about the veracity of COVID-19 claims; (d) trust in prominent politicians (e.g., The President of the United States) and health science/medical experts (e.g., World Health Organization) as sources of COVID-19 information; and (e) trust in science and scientific modeling to ensure efficacious COVID-19 response?

- Support for societal level COVID-19 mitigating response (i.e., support for future COVID-19 responses that include social distancing as an ethical commitment and not permitting large social gathering events where infection risk is high) was significantly associated with, in order of importance: (1) political orientation; (2) COVID- 
19 spread prevention knowledge; (3) beliefs about COVID-19 misinformation and disinformation; (4) trust in scientific models for guiding COVID-19 response and decision-making; and (5) beliefs that science and technology alone, sans personal action, will fix the pandemic.

- Higher levels of support for societal COVID-19 mitigating responses were associated with an advanced understanding of how COVID-19 spreads and trust in scientific models to guide COVID-19 decision-making.

- Increasingly politically conservative ideology, believing common COVID-19 misinformation and disinformation claims, and perceiving that science and technology alone, sans personal action, will resolve the COVID-19 pandemic were associated with lower levels of support for future COVID-19 responses.

- Trust in prominent health science/medical experts' as sources of COVID-19 information was not associated with levels of support for societal COVID-19 mitigating responses.

RQ2b.How does political orientation moderate reliance on science and trust in scientific models and health science/medical experts as sources of information for COVID-19 response when predicting university biology students' support for societal COVID-19 responses?

- No significant interactions were present.

\section{Limitations}

Several limitations must be noted regarding this investigation. First, while the investigation involved a respectable sample size of university biology students, we can only assume that they are academically, socially, and demographically similar to the larger sample of the 1,420 undergraduates enrolled across the three biology courses. We hesitate to state that the participants investigated here were fully representative of the larger pool of students. This is an unfortunate and typical consequence of studies, such as this one, that are limited to a non-randomized self-selection processes where (1) self-selected participants may exhibit characteristics (e.g., higher levels of altruism and efficacy to complete surveys) that are lacking in some non-participants; and (2) no information is collected about non-participants. Despite this limitation, the sample exhibited sufficient size and variance to carry out the necessary statistical methods to robustly answer this investigation's research questions.

A second concern may arise that because surveys were completed from April 21 to May 5, participants' thinking and beliefs about science at the time of completing the survey may have changed from their thinking during the 2 weeks following the March 31 stay-athome order when they committed COVID-19 mitigating actions. Our rationale for asking students about their actions after the government imposed order is that the order coincided with and was rationalized through alarming COVID-19 fatality projections, such as those announced by the U.S. President and portrayed through scientific models familiar to the students. Therefore, we perceive that these events created a concrete context that would prompt students' judicious action, and their deeply remembering those actions. Much scholarship has been conducted regarding the durable nature of peoples' science conceptions, particularly regarding NOS issues (Hodson, 2009; Lederman, 2007). In light of this scholarship, we consider it is highly unlikely that the students' knowledge and beliefs would have changed over such a short course of time. However, to safeguard against such 
an event, we only focused on students who, using their knowledge and beliefs at the time of survey completion, advocated that their COVID-19 mitigating actions were appropriate during the 2 weeks following the stay-at-home order (see "Sect. 4.2").

Lastly, while the students' thinking and actions were assessed in the midst of their experiencing a real-world SSI of the COVID-19 pandemic, those assessments were in the form of self-report. Measuring students' actual actions instead of their intentions and willingness to act adds methodological robustness to this study (Herman, 2018; Gifford \& Nilsson, 2014; Kormos \& Gifford, 2014). However, the research is ambiguous regarding the extent that people may skew how they self-report health and environmental actions that are tied to social and ideological expectations (Brener et al., 2003; Milfont, 2009; Studts et al., 2006; Stern \& Oskamp, 1987; Tarrant \& Cordell, 1997). We do recognize that response bias may be a more serious concern if it is perceived by respondents that their actions would be lauded or condemned by the sociocultural groups they identify with. Our ensuring the participants that their response would remain confidential and asking them to confirm the appropriateness of their COVID-19 mitigating actions should help to mitigate this concern. Future studies that focus on socioscientific decision-making should attempt to collect other forms of data (e.g., qualitative observations and interviews) that can further confirm participants' actions.

\section{Discussion and Implications}

Study participants' basic knowledge about COVID-19 and how to mitigate its spread were generally quite high (means of 81 and 93, respectively, on a scale of 0 to 100). Among our study participants, possessing accurate knowledge about how COVID-19 spreads and not accepting related misinformation and disinformation was most highly associated with enacting personal COVID-19 mitigating behavior and supporting societal mitigation policies. However, this basic COVID-19 knowledge (see Table 4) is to a large extent related to, or at least not at odds with, more general knowledge about viruses and their spread; ideas that study participants likely already accepted (e.g., washing hands, distancing oneself from those who are sick, and being able to spread an illness even when not exhibiting symptoms). This and other COVID-19 knowledge and beliefs appearing in Table 4 would unlikely be perceived as contentious, by those just completing an undergraduate biology course with instruction on pathogens. Thus, as noted in the literature review, trust is largely tacit.

If personal and societal decision-making were solely a function of possessing this accurate scientific knowledge, then study participants' COVID-19 mitigating personal actions and support for mitigating social policies would likely be much higher than was the case. As noted in the literature review, when a SSI is perceived, correctly or not, as contentious, trust is no longer tacit. In these situations, science itself comes under scrutiny and the sociocultural factors that are always at play can and often do impact, in complex ways, the relationship between beliefs about science, the veracity of scientific knowledge, and socioscientific decision-making (Herman, 2015, 2018; Hodson, 2009; NASEM, 2017). What those sociocultural factors entail and how they impacted COVID-19 thinking and decisionmaking are the crux of the study reported here.

For instance, as our study participants' self-identified political orientation became increasingly conservative, their self-reported COVID-19 personal mitigating behaviors decreased as did their support for societal level policies going forward. In contrast, liberal 
political orientations were associated with increased COVID-19 mitigating actions and support for societal mitigating policies. Participants' political orientation, even more so than for their personal COVID-19 actions, predicted support for societal-level action going forward. This may reflect the greater ease in supporting a position, public policy, and/or response than exerting the personal effort and possible sacrifice of carrying out an action (Herman, 2015, 2018; Kormoss \& Gifford, 2014) and/or it may reflect the importance of affiliating with one's political tribe when SSI-related choices and policy become more contentious (Kahan et al., 2007; McCright et al., 2014). Females in our study also were significantly more likely to engage in COVID-19 mitigating actions. These findings align with prior research indicating that being male and increasing political conservatism are associated with lower levels of risk perception about environmental hazards, which can reduce engagement in and support for social behaviors that reduce risk to people and the environment (Finucane et al., 2000; Flynn et al., 1994). Not surprisingly, the view among study participants that science and technology, sans personal action, would resolve the pandemic was negatively associated with support for societal level COVID-19 mitigating response.

This investigation demonstrates that science beliefs and trust, and their impact on SSI resolution, become increasingly complex when accounting for people's sociocultural group membership. For instance, regression analyses showed that participants' perceptions of the trustworthiness and accuracy of health science/medical experts' (e.g., World Health Organization and Dr. Anthony Fauci, Director of the U.S. National Institute of Allergy and Infectious Diseases and the chief medical advisor to the president) COVID-19 guidance did not significantly associate with personal COVID-19 mitigating actions or support for societal level COVID-19 actions going forward. However, that trust was significantly, albeit weakly, negatively correlated with an increasingly conservative political ideology and trust in U.S. President Trump's COVID-19 guidance. Furthermore, knowledge about how COVID-19 spreads and trust in scientific models to guide COVID-19 pandemic response was weakly to moderately and negatively correlated with espousing increasingly conservative political orientations and trust for the Presidents' guidance. Alternatively, such conservative political leanings and trust in President Trump's COVID-19 guidance were positively correlated, to a modest extent, in believing in the veracity of COVID-19 misinformation and disinformation. The correlational relationships described here were not a primary focus of this study. However, they do appear to demonstrate, in line with studies regarding climate change (Kahan, 2015), that a lack of trust in the veracity of scientific knowledge or its source is not always the real culprit. The main issue is often how group membership may impact what kinds of scientific knowledge you accept as legitimate and what sources of information you trust. Our future COVID-19 studies are looking at this dynamic interplay more closely through more in-depth qualitative (e.g., interviews of participants) and quantitative (e.g., structural equation modeling) approaches.

The complex interplay between sociocultural group affiliation, trust in science, and action became more evident when analyzing how study participants' political orientation moderated the relationship between their trust in scientific models to guide COVID-19 response and the students' COVID-19 mitigating actions. At the time of data collection, these models were increasingly profiled in the media and political briefings delivered by prominent figures such as the U.S. President. Because COVID-19 models are necessarily based on assumptions, some that change with time and incoming information, their projections changed. The changing projections were often misunderstood and their inherent uncertainty was inappropriately used by politicians as a way to instill distrust among the public - particularly among conservatives (for example, see Wan \& Blake, 2020). In a sense, this scenario resembles warnings from scholars such as Rudolph (2007) who rightly 
argue that businesses, special interest groups, and political figures may leverage the public's insufficient NOS knowledge to imbue unreasonable doubt among them about reliable scientific work, which can impact socioscientific decision-making to the detriment of human and environmental health.

For study participants who identified as liberal and very liberal, trust in scientific models to guide COVID-19 decision-making was not associated with their personal COVID-19 actions. Politically liberal participants' COVID-19 actions appear to reflect the norms of their sociocultural group, and appear to largely be irrespective of their contemplated trust in the COVID-19 models - prudent actions for imprudent reasons! For politically conservative study participants, those having higher levels of trust in scientific models to guide COVID-19 decision-making positively predicted personal COVID-19 actions. The extent they trusted COVID-19 models mattered a great deal, particularly the more conservative they were. Thus, perhaps a politically left orientation may have marginalized critical thinking regarding the COVID-19 models, while a politically right orientation appears to require compelling reasons to trust the COVID-19 models. At both ends of the political spectrum, sociocultural group membership appears to play an important, yet convoluted, role regarding how people consider and trust important scientific information when making decisions and supporting policy to resolve SSI.

Foregrounding of group identity for any reason is disconcerting because the group to which allegiance is given does not and will not possess the truth in all matters. Study participants politically oriented to the left made more appropriate personal and societal COVID-19 mitigating decisions, but apparently this was not wholeheartedly because of an increased understanding of or trust in the COVID-19 models. Study participants holding moderate to conservative political orientations may have noted the inherent uncertainty in the scientific models, which again was inappropriately leveraged by conservative political figures at the time of this study, and foregrounded that to justify their personal actions and thinking. From a pragmatic perspective, in the midst of the COVID-19 pandemic, science communicators' and policymakers' efforts may have been best directed at those whose trust in science can be augmented in a way that makes clear what can be confidently stated while acknowledging uncertainty. Efforts to promote more judicious decision-making can be achieved (Bavel et al., 2020; Schenk et al., 2019), but presuming and foregrounding science knowledge deficits is often incorrect and even counter-productive (NASEM, 2017).

The issue of trust in science and science communication that will increase that trust is complex. Sociocultural factors play a prominent role, and bludgeoning the public with more science information does not address the sociocultural lenses through which such efforts and the scientific knowledge itself are seen. In the study reported here, study participants with a political left orientation appeared to adopt actions consistent with their group identity, not because they better understood or trusted the COVID-19 models. Study participants with a political right orientation were generally distrustful of the COVID-19 models, and this was associated with greater caution or resistance to COVID-19 mitigating policies. Those at both ends of the political spectrum appeared to foreground their ideology and sociocultural identity in their sense-making and decision-making. This focus seemed to interfer with study participants' fair assessment of the science, even though their schooling in science exceeds that of most citizens.

We wish to revisit our previous statement that group membership may impact what kinds of scientific knowledge are accepted as legitimate and what sources of information are trusted. The extent that sociocultural biases influence how and what scientific work and information people, at all levels of society, trust and base decisions upon became more evident as the pandemic proceeded. This was, and still is, illustrated via the robust support 
for and dissemination of COVID-19 information by pseudoscience purveyors and even by individual and small groups of scientists possessing legitimate credentials, but either are not epidemiology experts and/or are those holding views at odds with the vetted and broad consensus of the community of infectious disease specialists. These unsubstantiated rogue claims are, instead, shamelessly promulgated via mainstream and social media, and embraced by particular policymakers and portions of the public who find them ideologically resonating.

For instance, on October 4, 2020, Martin Kulldorff, Professor of Medicine at Harvard Medical School, Sunetra Gupta, Professor of Theoretical Epidemiology at Oxford University, and Jay Bhattacharya, Professor of Health Policy at Stanford University Medical School, authored an on-line petition called The Great Barrington Declaration, which advocates that COVID-19 should be controlled not through widespread lockdowns and eventual vaccinations, but through a "Focused Protection" approach where herd immunity could be reached by (1) allowing the virus to spread naturally and unobstructed among younger people who are at lower risk from developing serious disease and dying; while also (2) simultaneously protecting older and higher risk individuals from community transmission. The declaration signing was hosted by the libertarian think tank the American Institute for Economic Research, video recorded, and posted to YouTube in an apparent appeal to the broader public; rather than be scrutinized by the scientific community through formal review.

The condemnation of the Great Barrington Declaration by the community of experts was swift and occurred through more credible means than those used to propose the Declaration. For instance, the John Snow Memorandum, named after the English physician who is considered one of the founders of epidemiology because of his source tracing during a cholera outbreak in 1854, published in the Lancet, and signed by more than 6,900 scientists, researchers, and healthcare professionals, warned that herd immunity approaches such as those proposed by the Great Barrington Declaration are a "dangerous fallacy unsupported by scientific evidence" (Alwan, et al., 2020). Pointing out that political group membership may cause some to mistakenly perceive the Great Barrington Declaration to be a scientifically viable proposal, Francis Collins, Director of the National Institutes of Health in the United States, warned:

What I worry about with this is it's being presented as if it's a major alternative view that's held by large numbers of experts in the scientific community. That is not true...This is a fringe component of epidemiology. This is not mainstream science. It's dangerous. It fits into the political views of certain parts of our confused political establishment, I'm sure it will be an idea that someone can wrap themselves in as a justification for skipping wearing masks or social distancing and just doing whatever they damn well please (Achenbach, 2020).

Despite condemnation by the scientific community of experts, conservative mainstream media pundits and politicians lauded the Declaration seemingly because its proposed course of action appeared to align with their economic and liberty considerations (see Ingraham, 2020; Pudzer, 2020); with even the U.S. President and some his advisors praising the merits of the proposal as a viable response to the pandemic (Achenbach, 2020). Furthermore, the Declaration was also shared widely on social media platforms as a noteworthy alternative view of the scientific community.

We address this occurrence to illuminate how the Great Barrington Declaration garnered undeserved attention and credibility because of the extent that contemporary media platforms distribute controversial and unsubstantiated propositions advanced by scientists dissenting from the community of experts. Without extensive media exposure, the 
scientific community of experts would have vetted the Declaration, and protected the public from that information. However, that this "open science" scenario played out in the media because of political reasons largely served to undermine public trust in the community of experts who put forth viable recommendations to mitigate the pandemic based on the most veracious science at the time.

The COVID-19 pandemic is the latest and perhaps the most high-profile SSI illustrating the challenge for science education. An education in science would foreground what is known about the natural world and how we know it - addressing science-in-the-making and the vetting processes that over time mitigates bias and results in reliable knowledge. This entails a plethora of crucial NOS issues, many that can and do play a role in SSI decision-making. But even more is required. Citizens must be educated to understand and overtly consider how sociocultural factors impact reasoning, trust, and decision-making; their own as well as others. With SSI, respectful educative efforts must make overt the relevant and accurate science content (well-established and in-the-making) and NOS understanding, inaccurate science content and how we know it is so, relevant sociocultural factors (including identities), and how all of these can and do impact decision-making. A full awareness of all of these factors, along with a fair and open discussion of likely outcomes of various decisions, would likely improve critical thinking and develop appropriate understanding of who to trust and why when dealing with personal and societal issues involving science. This educative approach is likely also the only way out of the polarized identitydriven debacle society finds itself.

Funding The research leading to these results received funding from the National Science Foundation Improving Undergraduate STEM Education (IUSE) Program under Award Number: 2032737. Any opinions, findings, and conclusions or recommendations expressed in this manuscript are those of the authors and do not necessarily reflect the views of the National Science Foundation. The authors have no other relevant financial or non-financial interests to disclose.

\section{References}

Achenbach, J. (2020). Proposal to hasten herd immunity to the coronavirus grabs White House attention but appalls top scientists. The Washington Post. https://www.washingtonpost.com/health/covid-herdimmunity/2020/10/10/3910251c-0a60-11eb-859b-f9c27abe638d_story.html, Accessed 10/18/2021.

Allchin, D. (2011). Evaluating knowledge of the nature of (Whole) Science. Science Education, 95(3), 918-942.

Allchin, D. (2012). Toward clarity on whole science and KNOWS. Science Education, 96(4), 693-700.

Allen, E., \& Seaman, C. (2007). Likert scales and data analyses. Quality Progress, 40(7), 64-65.

Alwan, N. A., Burgess, R. A., Ashworth, S., Beale, R., Bhadelia, N., Bogaert, D., Dowd, J., Eckerle, I., Goldman, L. R., Greenhalgh, T., et al. (2020). Scientific consensus on the COVID-19 pandemic: We need to act now. Lancet, 396, e71-e72.

Barzilai, S., \& Chinn, C. A. (2020). A review of educational responses to the "post-truth" condition: Four lenses on "post-truth" problems. Educational Psychologist, 55(3), 107-119.

Baruch, Y. (1999). Response rate in academic studies-A comparative analysis. Human Relations, 52, 421-438.

Bavel, J. J. V., Baicker, K., Boggio, P. S., et al. (2020). Using social and behavioural science to support COVID-19 pandemic response. Nature Human Behaviour, 4, 460-471. https://doi.org/10.1038/ s41562-020-0884-Z

Beavers, A. S., Lounsbury, J. W., Richards, J. K., Huck, S. W., Skolits, G. J., \& Esquivel, S. L. (2013). Practical considerations for using exploratory factor analysis in educational research. Practical Assessment, Research \& Evaluation, 18(6), 1-13. 
Bell, P., \& Linn, M. C. (2002). Beliefs about science: How does science instruction contribute? In B. Hofer \& P. R. Pintrich (Eds.), Personal epistemology: The psychology of beliefs about knowledge and knowing (pp. 321-346). Erlbaum.

Bennett, J. (2001). The development and use of an instrument to assess students' attitude to the study of chemistry. International Journal of Science Education, 23(8), 833-845.

Bishop, P. A., \& Herron, R. L. (2015). Use and misuse of the Likert item responses and other ordinal measures. International Journal of Exercise Science, 8, 297-302.

Brener, N. D., Billy, J. O. G., \& Grady, W. R. (2003). Assessment of factors affecting the validity of selfreported health-risk behavior among adolescents: Evidence from the scientific literature. Journal of Adolescent Health, 33, 436-457. https://doi.org/10.1016/S1054-139X(03)00052-1

Briggs, S. R., \& Cheek, J. M. (1986). The role of factor analysis in the development and evaluation of personality scales. Journal of Personality, 54(1), 106-148.

Brush, S. G. (1974). Should the history of science be rated X? Science, 183(4130), 1164-1172.

Carifio, L., \& Perla, R. (2008). Resolving the 50 year debate around using and misusing Likert scales. Medical Education, 42(12), 1150-1152.

Centers for Disease Control (CDC) (2020) Coronavirus disease (COVID-19) frequently asked questions. Retrieved, April 10, 2020 from: https://www.cdc.gov/coronavirus/2019-ncov/faq.html.

Chinn, C. A., Barzilai, S., \& Duncan, R. G. (2021). Education for a "post-truth" world: New directions for research and practice. Educational Researcher, 50(1), 51-60. https://doi.org/10.3102/0013189X20 940683

Clark, L. A., \& Watson, D. (1995). Constructing validity: Basic issues in objective scale development. Psychological Assessment, 7(3), 309-319.

Clough, M. P. \& Herman, B. C. (2017). The role of history and nature of science in climate change teaching and learning. In Shepardson, D., Roychoudhury, A. \& Hirsch, A. (Eds.) Teaching and Learning about Climate Change: A Framework for Educators. Routledge.

Cobern, W. W. (1993). Contextual constructivism: The impact of culture on the learning and teaching of science. In K. G. Tobin (Ed.), The practice of constructivism in science education (pp. 51-69). Erlbaum.

Cobern, W. W. (1996). Worldview theory and conceptual change in science education. Science Education, $80(5), 579-610$.

Cohen, J. (1992). A power primer. Psychological Bulletin, 112, 155-159.

Darlington, R. B., \& Hayes, A. F. (2017). Regression analysis and linear models: Concepts, application, and implementation. The GuilfordPress.

diSessa, A. A., Elby, A., \& Hammer, D. (2002). J's epistemological stance and strategies. In G. M. Sinatra \& P. R. Pintrich (Eds.), Intentional conceptual change (pp. 237-290). Erlbaum.

Fagerlin, A., Wang, C., \& Ubel, P. A. (2005). Reducing the influence of anecdotal reasoning on people's health care decisions: Is a picture worth a thousand statistics? Medical Decision Making, 25, 398-405.

Feldman, L., Maibach, E. W., Roser-Renouf, C., \& Leiserowitz, A. (2012). Climate on cable: The nature and impact of global warming coverage on Fox News, CNN, and MSNBC. International Journal of Press/ politics, 17(1), 3-31.

Finucane, M. L., Slovic, P., Mertz, C. K., Flynn, J., \& Satterfield, T. A. (2000). Gender, race, and perceived risk: The "white male" effect. Health, Risk \& Society, 2(2), 159-172.

Flynn, J., Slovic, P., \& Mertz, C. K. (1994). Gender, race, and perception of environmental health risks. Risk Analysis, 14(6), 1101-1108.

Gauchat, G. (2011). The cultural authority of science: Public trust and acceptance of organized science. Public Understanding of Science, 20, 751-770.

Gauchat, G. W. (2012). Politicization of science in the public sphere: A study of public trust in the United States, 1974 to 2010. American Sociological Review, 77(2), 167-187.

Gifford, R., \& Nilsson, A. (2014). Personal and social factors that influence pro-environmental concern and behaviour: A review. International Journal of Psychology, 49(3), 141-157.

Harker, D. (2015). Creating scientific controversies: Uncertainty and bias in science and society. Cambridge University Press.

Herman, B. C. (2013). Convergence of Postman and Vygotsky's perspectives regarding contemporary media's impact on learning and teaching. Chapter 15 (pp. 293-328) in M. P. Clough, J. K. Olson \& D. S. Niederhausers (Eds.) The Nature of Technology: Implications for Teaching and Learning, Rotterdam: Sense Publishers.

Herman, B. C. (2015). The influence of global warming science views and sociocultural factors on willingness to mitigate global warming, Science Education. 1(1), 1-38.

Herman, B. C. (2018). Students' environmental NOS views, compassion, intent, and action: Impact of placebased socioscientific issues instruction. Journal of Research in Science Teaching, 55(4), 600-638. 
Herman, B. C., Newton, M. H., \& Zeider, D. (2021). Impact of place-based socioscientific issues instruction on students' contextualization of socioscientific orientations. Science Education. https://doi.org/ 10.1002/sce.21618.

Herman, B. C., Zeidler, D. L. \& Newton, M. H. (2020). Emotive reasoning through place-based environmental socioscientific issues. Research in Science Education, 50, 2081-2109.

Hodson, D. (2009). Teaching and learning about science: Language, theories, methods, history, traditions and values. Sense Publishers.

Hon, L.C. \& Grunig, J.E. (1999). Guidelines for measuring relationships in public relations. Available at https://instituteforpr.org/wp-content/uploads/Guidelines_Measuring_Relationships.pdf (posted January 16,2011$)$, p. 3.

Ingraham, L. (2020). Ingraham: Dems hoped COVID-19 would fix what impeachment couldn't. Fox News, Retrieved on 10/12/2020 from: https://www.foxnews.com/transcript/ingraham-dems-hoped-covid-19would-fix-what-impeachment-couldnt

Kahan, D. M. (2013). Ideology, motivated reasoning, and cognitive reflection. Judgment and Decision Making, 8, 407-424.

Kahan, D. M. (2015). Climate-science communication and the measurement problem. Advances in Political Psychology, 36, 1-43.

Kahan, D. M., Braman, D., Gastil, J., Slovic, P., \& Mertz, C. K. (2007). Culture and identity-protective cognition: Explaining the White-male effect in risk perception. Journal of Empirical Legal Studies, 4, 465-505. Retrieved from http://papers.ssrn.com/sol3/papers.cfm?abstract_id=995634

Kahan, D. M., Jenkins-Smith, H., \& Braman, D. (2011). Cultural cognition of scientific consensus. Journal of Risk Research., 14, 147-174.

Kahan, D. M., Peters, E., Wittlin, M., Slovic, P., Ouellette, L. L., Braman, D., \& Mandel, G. (2012). The polarizing impact of science literacy and numeracy on perceived climate change risks. Nature Climate Change, 2, 732-735.

Keith, T. Z. (2019). Multiple regression and beyond: An introduction to multiple regression and structural equation modeling. (3rd ed.). New York: Routledge.

Kline, R. B. (2016). Principles and practice of structural equation modeling (4th ed.). Guilford Press.

Kormos, C., \& Gifford, R. (2014). The validity of self-report measures of proenvironmental behavior: A metaanalytic review. Journal of Environmental Psychology, 40, 359-371.

Kromrey, J. D., \& Foster-Johnson, L. (1998). Mean centering in moderated multiple regression: Much ado about nothing. Educational and Psychological Measurement, 58

Latour, B. (1987). Science in action. Harvard University Press.

Latour, B. (2004). Why has critique run out of steam? From matters of fact to matters of concern. Critical Inquiry, 30(2), 225-248.

Leach, J., Millar, R., Ryder, J., \& Sere, M. G. (2000). Epistemological understanding in science learning: The consistency of representations across contexts. Learning and Instruction, 10(6), 497-527.

Lederman, N. G. (2007). Nature of science: Past, present, and future. In S. K. Abell \& N. G. Lederman (Eds.), Handbook of research in science education (pp. 831-879). Lawrence Erlbaum Publishers.

Lewandowsky, S., Gignac, G. E., \& Oberauer, K. (2013). The role of conspiracist ideation and worldviews in predicting rejection of science. PLOS ONE, 8(10), e75637. https://doi.org/10.1371/journal. pone. 0075637

Louca, L., Elby, A., Hammer, D., \& Kagey, T. (2004). Epistemological resources: Applying a new epistemological framework to science instruction. Educational Psychologist, 39(1), 57-68.

Lynch, D., \& McKenna, M. (1990). Teaching controversial material: New issues for teachers. Social Education, 54(5), 317-319.

McCright, A. M., Dunlap, R. E., \& Xiao, C. (2014). The impacts of temperature anomalies and political orientation on perceived winter warming. Nature Climate Change, 4, 1077-1081.

McComas, W. F., Clough, M. P., \& Almazroa, H. (1998). The role and character of the nature of science in science education. In W. F. McComas (Ed.), The nature of science in science education: Rationales and strategies (pp. 3-39). Kluwer.

Milfont, T. L. (2009). The effects of social desirability on self-reported environmental attitudes and ecological behaviour. The Environmentalist, 29, 263e269. https://doi.org/10.1007/s10669-008-9192-2

Mitchell, S. D. (2009). Unsimple truths: Science, complexity, and policy. University of Chicago Press.

Mondak, J. (1988). Protest music as political persuasion. Popular Music and Society, 12, 25-38.

Nadelson, L. S., \& Hardy, K. K. (2015). Trust in science and scientists and the acceptance of evolution. Evolution: Education and Outreach, 8, 9.https://doi.org/10.1186/s12052-015-0037-4

National Academies of Sciences, Engineering, and Medicine (2017). Communicating science effectively: A research agenda. Washington: The National Academies Press. https://doi.org/10.17226/23674. 
National Science Board. (2016). Science and technology: Public attitudes and understanding. Chapter 7 in Science and Engineering Indicators 2016. Arlington, VA: National Science Foundation. Available at https://www.nsf.gov/statistics/2016/nsb20161/uploads/1/10/chapter-7.pdf

Nichols, T. (2017). The death of expertise: The campaign against established knowledge and why it matters. Oxford University Press.

Norman, G. (2010). Likert scales, levels of measurement and the "laws" of statistics. Advances in Health Sciences Education, 15(5), 625-632.

Osborne, J., Simon, S., \& Collins, S. (2003). Attitude towards science: A review of the literature and its implications. International Journal of Science Education, 25(9), 1049-1079.

Oulton, C., Dillon, J., \& Grace, M. M. (2004). Reconceptualizing the teaching of controversial issues. International Journal of Science Education, 26(4), 411-423.

Pew Research Center. (2015). Public and scientists' views on science and society. Available at https:// www.pewresearch.org/science/2015/01/29/public-and-scientists-views-on-science-and-society/

Powell, J. L. (2016). The consensus on anthropogenic global warming matters. Bulletin of Science, Technology, \& Society, 36(3), 157-163.

Pudzer, A. (2020). Dems want science, they should look at the Great Barrington Declaration. Fox News, https://www.foxnews.com/opinion/covid-lockdown-science-great-barrington-declaration-andy-puzder, Accessed 18 Oct 2021.

Rahn, W. M., \& Transue, J. E. (1998). Social trust and value change: The decline of social capital in American youth, 1976-1995. Political Psychology, 19(3), 545-565.

Roduta-Roberts, M., Reid, G., Schroeder, M., \& Norris, S. P. (2011). Causal or spurious? The relationship of knowledge and attitudes to trust in science and technology. Public Understanding of Science, 22(5), 624-641.

Schenk, L., Hamza, K. M., Enghag, M., Lundegård, I., Arvanitis, L., Haglund, K., \& Wojcik, A. (2019). Teaching and discussing about risk: Seven elements of potential significance for science education. International Journal of Science Education, 41(9), 1271-1286. https://doi.org/10.1080/09500693. 2019.1606961

Stern, P. C., \& Oskamp, S. (1987). Managing scarce environmental resources. In D. Stokols \& I. Altman (Eds.), Handbook of environmental psychology (pp. 1043-1088). Wiley.

Streiner, D. L. (1994). Figuring out factors: The use and misuse of factor analysis. Canadian Journal of Psychiatry, 39(3), 135-140.

Studts, J. L., Ghate, S. R., Gill, J. L., Studts, C. R., Barnes, C. N., Lajoie, A. S., et al. (2006). Validity of self-reported smoking status among participants in a lung cancer screening trial. Cancer Epidemiology, Biomarkers \& Prevention, 15, 1825e1828. https://doi.org/10.1158/1055-9965.EPI-06-0393

Tabachnick, B. G., \& Fidell, L. S. (2007). Using multivariate statistics (5th ed.). Pearson Education.

Tarrant, M. A., \& Cordell, H. K. (1997). The effect of respondent characteristics on general environmental attitude-behavior correspondence. Environment \& Behavior, 29, 618e637. https://doi.org/10.1177/ 0013916597295002

United Nations (2019) World population prospects 2019: Highlights. Report by the United Nations Department of Economic and Social Affairs. https://www.un.org/development/desa/publications/world-popul ation-prospects-2019-highlights.html, Accessed 10/18/2021.

Vickers, A. (1999). Comparison of an ordinal and a continuous outcome measure of muscle soreness. International Journal of Technology Assessment in Health Care, 15, 709-716.

Wan, W. \& Blake, A. (2020). Coronavirus modelers factor in new public health risk: Accusations their work is a hoax. The Washington Post, March 27. https://www.washingtonpost.com/health/2020/03/27/coron avirus-models-politized-trump/, Accessed 05/19/2021.

World Health Organization (2020a). Timeline of WHO's response to COVID-19. https://www.who.int/newsroom/detail/29-06-2020-covidtimeline, Accessed 5/01/21.

World Health Organization (2020b). Naming the coronavirus disease (COVID-19) and the virus that causes it. https://www.who.int/emergencies/diseases/novel-coronavirus-2019/technical-guidance/naming-thecoronavirus-disease-(covid-2019)-and-the-virus-that-causes-it, Accessed 5/01/21.

World Health Organization. (2020c). Coronavirus disease (COVID-19) advice for the public: Mythbusters. Retrieved, April 10, 2020 from: https://www.who.int/emergencies/diseases/novel-coronavirus-2019/ advice-for-public/myth-busters.

Wong, S. L., Hodson, D., Kwan, J., \& Yung, B. H. W. Y. (2008). Turning crisis into opportunity: Enhancing student-Teachers' understanding of nature of science and scientific inquiry through a case study of the scientific research in severe acute respiratory syndrome. International Journal of Science Education, 30(11), 1417-1439.

Zeidler, D., Herman, B. C., Ruzek, M., Linder, A. \& Lin, S. S. (2013). Cross-cultural epistemological orientations to socioscientific issues. Journal of Research in Science Teaching, 50(3), 251-283. 
Publisher's Note Springer Nature remains neutral with regard to jurisdictional claims in published maps and institutional affiliations.

\section{Authors and Affiliations}

\section{Benjamin C. Herman ${ }^{1} \cdot$ Michael P. Clough $^{2} \cdot$ Asha Rao $^{3}$}

1 Department of Teaching, Learning \& Culture, Department of Biology, Texas A\&M University, 358 Harrington Tower, College Station, TX 77843-4232, USA

2 Department of Teaching, Learning \& Culture, Texas A\&M University, 335 Harrington Tower, College Station, TX 77843-4232, USA

3 Department of Biology, Texas A\&M University, 320 Heldenfels Hall, College Station, TX 77843-3258, USA 